\title{
An Evapotranspiration-Interception Model for Urban Areas
}

\author{
C. S. B. GRIMMOND ${ }^{1}$ AND T. R. OKE
}

Atmospheric Science Programme, Department of Geography. University of British Columbia, Vancouver, Canada

\begin{abstract}
A model to calculate evapotranspiration from urban areas over a wide range of meteorological conditions is presented. An evapotranspiration-interception approach is used because it is necessary to cope with the changing water availability on the surface, during and following rainfall or irrigation. The model is applicable to areas ranging from the size of city blocks to land use zones and time periods of one hour and longer. The modeled evaporation is compared with that from micrometeorological measurements conducted from January to June 1987 in a suburb of Vancouver, British Columbia, Canada. The results show that this approach to modeling urban evapotranspiration provides realistic hourly and daily estimates of the areally averaged latent heat flux and surface water state.
\end{abstract}

\section{INTRODUCTION}

Evapotranspiration $(E)$, the mass equivalent of the latent heat energy flux, is the term that links the energy and the water balances. For urban areas the water balance is written

$$
P+I+F=E+r+\Delta S+\Delta A \quad \mathrm{~mm} \mathrm{hr}^{-1}
$$

where $P$ is precipitation, $I$ is piped water supply, $F$ is water released due to anthropogenic activities, $r$ is runoff, $\Delta S$ is the change in water storage for the period of interest, and $\Delta A$ is net moisture advection; the urban energy balance is written

$$
Q^{*}+Q_{F}=Q_{E}+Q_{H}+\Delta Q_{S}+\Delta Q_{A} \quad W \mathrm{~m}^{-2}
$$

where $Q^{*}$ is net all-wave radiation, $Q_{F}$ is the energy released due to anthropogenic activities, $Q_{H}$ is the sensible heat flux, $\Delta Q_{S}$ is the storage heat flux, and $\Delta Q_{A}$ is the net heat advection; $Q_{E}=L_{v} E$ where $L_{v}$ is the latent heat of vaporization. These balances apply to the top of a volume which extends to sufficient depth that vertical heat and water exchange is negligible. Fluxes are determined per unit area of the top of the volume. A fuller explanation of this concept is given by $O k e$ [1988].

Evaporation from urban areas has been assumed to be considerably less than that from neighboring rural areas because of the supposed contrast between the hydrologic properties of building materials and vegetation-covered soils [e.g., Chandler, 1976]. Recent work by Kalanda et al. [1980], Cleugh and Oke [1986], and Grimmond and Oke [1986] shows that evaporation has a larger magnitude than originally thought, for example, in a temperate city (Vancouver, British Columbia (B.C.)) evaporation has been shown to constitute $38 \%$ of the losses of the annual external water balance and $81 \%$ of the losses of the summer water balance [Grimmond and Oke, 1986].

Urban evaporation has received little attention in the fields of both urban climatology and urban hydrology. Indeed, it hardly rates mention in textbooks on the subject [e.g., Lazaro, 1979; Landsberg, 1981; Hall, 1984]. In most urban

\footnotetext{
'Now at Climate and Meteorology Program, Department of Geography, Indiana University, Bloomington.

Copyright 1991 by the American Geophysical Union.

Paper number 91WR00557.

$0043-1397 / 91 / 91$ WR-00557\$05.00
}

hydrologic work, evapotranspiration is either ignored or dealt with via evaporation pan data [e.g., Alley et al., 1980; Wenzell and Voorhees, 1980; Sman et al., 1988] so that van den Ven [1988] concludes that the weakest point in the study of the urban water balance remains the estimation of evapotranspiration.

A model for use in conjunction with available runoff models to determine continuous hourly evapotranspiration would be useful to model water quantity, water quality, and urban climate. For water quantity it is of interest to be able to predict the surface water storage status. A recent trend in urban runoff work favors continuous simulation rather than modeling the runoff from individual rainfall events. Between-event simulation makes it necessary to account not only for the runoff but also for the other components of the water balance, including evaporation. For water quality modeling it is necessary to know the volumes of water present in order to calculate pollutant concentrations. In urban climatology there is a greater awareness of the evaporative term because of its role in the amelioration of thermal climate, even so there are only a few studies.

Models to determine the evapotranspiration from urban areas can be divided into two groups. First, there are those which consider $Q_{E}$ as one flux in the total surface energy balance. These are one-, two-, and quasi-three-dimensional numerical boundary layer models. The convective $Q_{H}$ and $Q_{E}$ fluxes are often partitioned using a surface moisture availability factor or an assumed Bowen ratio $(\beta)$. After attempting to validate three such urban climate models against measured energy balance fluxes (for dry summertime conditions), Ross and Oke [1988] conclude that $Q_{E}$ is the poorest of the fluxes simulated. The second group includes simple statistical algorithms and physically based models utilizing hydrometeorological data as input.

The objective of this paper is to present a physically based model to estimate hourly, and longer-period, evapotranspiration associated with urban units ranging in size from city blocks to land use zones.

\section{THE Model}

If evapotranspiration is to be calculated under diverse meteorological conditions, it is necessary for a model to cope with changing water availability on the surface during and following rainfall. Further, since the physical structure of the city has been compared to that of a forest with its 


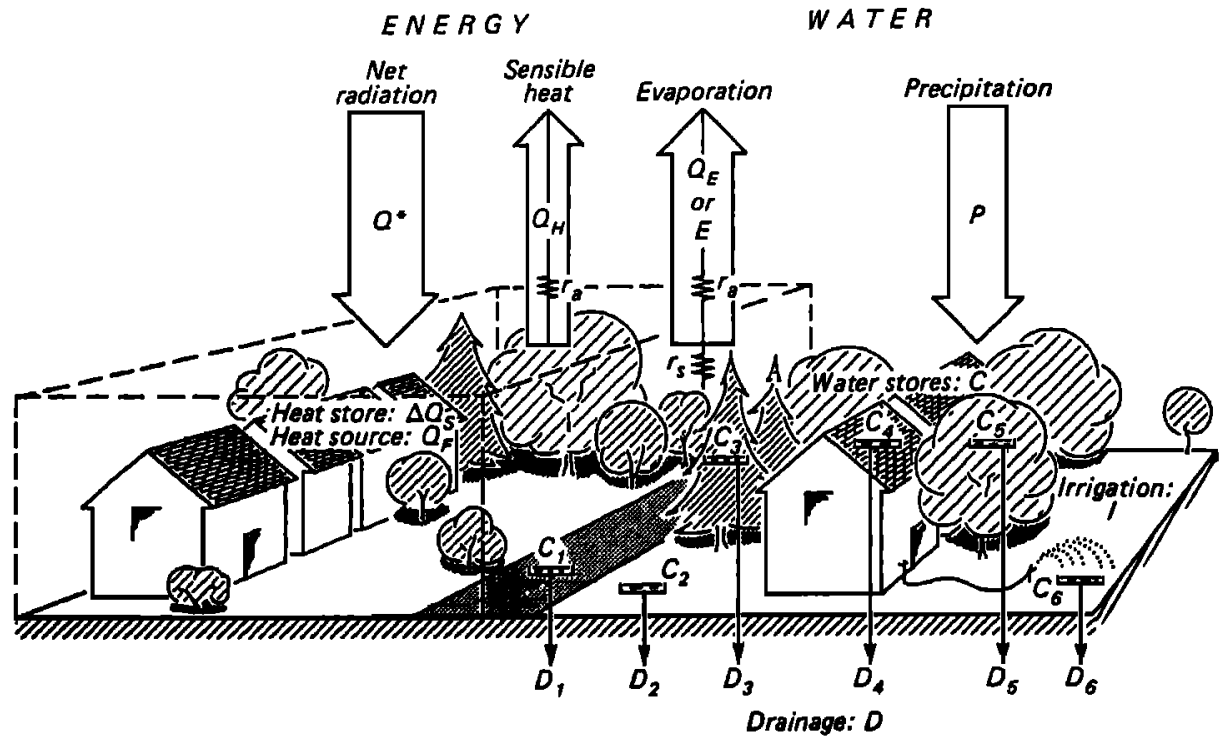

Fig. 1. Schematic of the conceptual framework of the model.

canopy, an evapotranspiration-interception approach similar to that used for forests is adopted. The urban canopy layer consists of the air contained between the buildings and trees. We propose an appropriate framework for urban evapotranspiration to be the Penman-Monteith-Rutter-Shuttleworth evapotranspiration-interception model which was originally developed for forests [Penman, 1948; Monteith, 1965; Rutter et al., 1971; Shuttleworth, 1978]. It is the most successful, rigorous, robust, physically based evapotranspirationinterception model currently available [Gash, 1979; Shuttleworth, 1983, 1989]. In essence, the model calculates a running water balance of the "canopy" and "trunks." It requires inputs of hourly rainfall and meteorological parameters and provides outputs of throughfall, stemflow, and evaporation of intercepted water. Evaporation is calculated from the Penman-Monteith equation. The model allows for a continuous treatment of surface resistance for the transition between wet and dry surfaces.

The conceptual framework of this model, as adapted for urban areas, is shown in Figure 1. The following is an outline of the model and the adaptations incorporated so that it can be applied to urban areas.

The process of evapotranspiration from surfaces which have some vegetative cover can be considered to consist of three stages: (1) evaporation from a totally wet surface (due to intercepted water), (2) evapotranspiration from a partially wet surface, and (3) transpiration from a dry surface (water loss from outwardly dry vegetation via the stoma). To calculate $E$ at any time it is necessary to know the surface water state to determine which stage is applicable. The Rutter model can be used to calculate the state of the running water balance of the canopy $(C)$, summarized by the continuity equation

$$
\frac{d C}{d t}=P\left(1-T_{F}-T_{S}\right)-D-E \quad \mathrm{~mm} \mathrm{hr}^{-1}
$$

where $t$ is time, $T_{F}$ is the throughfall or proportion of rain falling directly to the ground through the gaps in the canopy, $T_{S}$ is the proportion of rain diverted to the "trunks," and $D$ is the drainage rate. In the original model the canopy is represented as a single-layer store of moisture filled by incoming rainfall. It is capable of holding a preset amount of water $S$ and drains at a rate $D$ expressed as an empirical function in proportion to the amount of water in the store. Throughfall represents water not available for evaporation from the canopy. Subsidiary evaporation may arise from trunks wetted by stemflow.

Adapting this to the urban environment, the canopy is treated as a single-layer moisture store, with parallel stores which allow for the range of different surface types found in urban areas. As a first approximation, the urban system consists of two surface types: built/impervious and vegetated. There is little relevance to the concept of throughfall for impervious surfaces (buildings, paved road, paths), and since urban trees usually have vegetation (grass) below, the water which falls between them is caught by the vegetation below. Therefore throughfall can be set to zero or a very small number for both the vegetated and built surface types.

In urban areas the subsidiary loss, due to "stemflow", from wetted trunks can be interpreted as that from walls of buildings and from trunks of the tall vegetation. Generally. walls are not wetted by stemflow from the roof because of roof guttering. It is possible for them to be wetted directly by driving rain, but they are not extensively wetted under normal rain [Lacy, 1977]. Further, since the surface area of actual tree trunks in the urban system is not large [Grimmond, 1988], urban stemflow is also set to zero. The piped water supply $(I)$ is an additional source of water to wet the urban canopy. Therefore by neglecting $T_{F}$ and $T_{S}$ but adding $I$ the model can be reformulated for urban areas to read

$$
\frac{d C_{i}}{d t}=\left(P+I_{i}\right)-D_{i}-E
$$

where subscript $i$ is the $i$ th surface type. In this study, six surface types are used to characterize the study area: paved. built, coniferous, deciduous, irrigated grass, and unirrigated grass. A running water balance is maintained for each surface, and the evaporative flux calculated for an individual 
TABLE 1. Hourly Input Data Requirements and Outputs Generated by the Model

\begin{tabular}{|c|c|}
\hline & Units \\
\hline $\begin{array}{l}\text { Rainfall }(P) \\
\text { Net radiation }\left(Q^{*}\right) \\
\text { Wind speed }(u) \\
\text { Wind direction }(\varphi) \\
\text { Standard deviation of } \varphi\left(\sigma_{\varphi}\right) \\
\text { Air temperature }\left(T_{d}\right) \\
\text { Wet-bulb temperature }\left(T_{w}\right) \\
\text { or relative humidity } \\
\text { Pressure }(p) \\
\text { Sensible heat flux }\left(Q_{H}\right) \text { or } \\
\text { temperature difference }\left(\Delta T_{d}\right) \\
\text { External water use }(w u) \\
\text { Leaf area index }(\mathrm{LAI}) \\
\text { Soil moisture deficit }(\delta \theta) \\
\text { Storage heat flux }\left(\Delta Q_{S}\right) \\
\text { Anthropogenic heat flux }\left(Q_{F}\right)\end{array}$ & $\begin{array}{l}\mathrm{mm} \mathrm{hr}^{-1} \\
\mathrm{~W} \mathrm{~m}^{-2} \\
\mathrm{~m} \mathrm{~s}^{-1} \\
\mathrm{deg}, \mathrm{rad} \\
\mathrm{deg}, \mathrm{rad} \\
{ }^{\circ} \mathrm{C} \\
{ }^{\circ} \mathrm{C} \\
\% \\
\mathrm{~Pa} \\
\mathrm{~W} \mathrm{~m}^{2} \\
\mathrm{~mm} \mathrm{hr}^{-1} \\
\mathrm{~mm}^{\mathrm{W} \mathrm{m}^{-2}} \\
\mathrm{~W} \mathrm{~m}^{-2}\end{array}$ \\
\hline $\begin{array}{l}\text { Latent heat flux }\left(Q_{E}\right) \\
\text { Evapotranspiration }(E) \\
\text { Cumulative evapotranspiration } \\
\text { Drainage }(D) \\
\text { Surface state* } \\
\text { Surface storage change } \\
\text { Aerodynamic resistance }\left(r_{a}\right) \\
\text { Surface resistances }\left(r_{s}\right)\end{array}$ & $\begin{array}{l}\mathrm{W} \mathrm{m}^{-2} \\
\mathrm{~mm} \mathrm{hr} \\
\mathrm{mm} \\
\mathrm{mm} \mathrm{hr} \\
\mathrm{mm} \\
\mathrm{mm} \mathrm{hr}^{-1} \\
\mathrm{~s} \mathrm{~m}^{-1} \\
\mathrm{~s} \mathrm{~m}^{-1}\end{array}$ \\
\hline
\end{tabular}

*For total area and each surface type.

hour is weighted for the abundance of the $i$ types occurring in the source area of the measurements (see section 3.1). The change in storage for the whole system is determined from the summation of all the surface types.

If it is assumed that the components of the urban surface are exposed to the same local scale climate, then a singlesource (layer) model can be used to determine the latent heat flux $\left(Q_{E}\right)$. The best tested approach is the Monteith [1965] version of the Penman equation [Stewart, 1984; Dolman et al., 1988]. In the urban case it is modified to read

$$
Q_{E}=\frac{s\left(Q^{*}+Q_{F}-\Delta Q_{S}\right)+\left(C_{a} V\right) / r_{a}}{s+\gamma\left(1+r_{S} / r_{a}\right)}
$$

where $s$ is the slope of the saturation vapor pressure versus temperature curve $\left(\mathrm{Pa}^{\circ} \mathrm{C}^{-1}\right), \gamma$ is the psychrometric "constant" $\left(\mathrm{Pa}{ }^{\circ} \mathrm{C}^{-1}\right), C_{a}$ is the heat capacity of the air $\left(\mathrm{J} \mathrm{m}^{-3}\right.$ $\left.{ }^{\circ} \mathrm{C}^{-1}\right), V$ is the vapor pressure deficit of the air $(\mathrm{Pa})$, and $r_{a}$ and $r_{s}$ are the aerodynamic and surface resistances $\left(\mathrm{s} \mathrm{m}^{-1}\right)$. In this form the resistances for sensible and latent heat are equal and related to the equivalent resistance for momentum (often called the aerodynamic resistance $r_{a}$ ). The anthropogenic heat flux $\left(Q_{F}\right)$ is included as an additional source term. The equation is applicable to dry surfaces (stage 3); when the surface is completely wet (stage 1), the $r_{S}$ term is set to zero.

The overlap between the evaporation of intercepted water and transpiration is poorly defined in the Rutter model [Shuttleworth, 1983]. To link the two stages, a physically continuous transition between wet and dry canopies is required. Shuttleworth [1978] proposed such a model in which $r_{S}$ is replaced by a redefined surface resistance $r_{S s}$, equal to $r_{s}$ in dry conditions and set to zero in wet conditions, with a smooth transition between the two depending on the fractional surface wetness. Shuttleworth's theoretical analysis has been tested over tall vegetation [Shuttleworth, 1978] and takes the form

$$
r_{s s}=\left[\frac{W}{r_{b}(s / \gamma+1)}\right]+\left[\frac{(1-W)}{r_{s}+r_{b}(s / \gamma+1)}\right]^{-1}-r_{b}(s / \gamma+1)
$$

where

$$
\begin{gathered}
W=1 \quad C \geq S \\
W=\frac{R-1}{R-S / C} \quad C<S \\
R=\frac{\left(r_{S} / r_{a}\right)\left(r_{a}-r_{b}\right)}{r_{S}+r_{b}(s / \gamma+1)}
\end{gathered}
$$

where $r_{b}=1.1 u_{*}^{-1}+5.6 u_{*}^{1 / 3}$ is the mean boundary layer resistance [Shuttleworth, 1983], and $u_{*}$ is frictional velocity $\left(\mathrm{m} \mathrm{s}^{-1}\right.$ ) (see section 3.4. for method of calculation).

The complete urban evapotranspiration-interception model uses submodels (see section 3) to identify and describe turbulent source areas and to calculate anthropogenic heat and storage heat fluxes, aerodynamic and surface resistances, drainage, and storage capacities. The model requires inputs to describe the surface and hourly meteorological data and provides outputs of surface water state and evapotranspiration (Table 1 ).

\section{SUBMODELS}

\subsection{Source Area Identification}

The urban atmosphere interface is extremely complex, defying simple description. For example, in a suburban land 
use zone it is possible at one scale to identify an area which could be considered homogeneous (e.g., a residential area), within which there is a large degree of smaller-scale heterogeneity (e.g., buildings, vegetation, roads). The collection of surface elements that are sampled by a micrometeorological sensor are termed its "source area." In urban areas the surface is not necessarily homogenous at the scales of the source areas of the turbulent fluxes. The turbulent source area is upwind of the measurement site and in the direction of the prevailing wind. Its upwind, downwind, and lateral boundaries are dependent on the characteristics of the flow and on the boundary layer development in the atmospheric layer between the surface and sensor level. Further, the turbulent fluxes measured at a point have a continuously changing source area due to the variations in the flow and stability of the boundary layer.

In order to model evapotranspiration it is necessary to have surface descriptive information for the calculation of $Q_{F}, \Delta Q_{S}, D$, surface resistance, and the overall $Q_{E}$. Therefore it is necessary to have a method to identify the appropriate source area and to retrieve the surface characteristics for the same area [Schmid et al., 1991]. To identify these areas, a modified version of the Schmid and Oke [1990] source area model was used. The inputs necessary to determine the weighted source areas are the site conditions (roughness and zero-plane displacement) and meteorological scaling parameters (Obukhov stability length, friction velocity, and either the standard deviation of wind direction and mean wind speed or the mixed layer depth). The output of the model consists of nine source area ellipses for each hour (Figure 2). The area between each ellipse has equal weight, that is, the area labeled " $a$ " contributes the same amount to the measured flux as that labeled " $b$ ". In the current work the Schmid and Oke [1990] model, which was developed for unstable conditions, was extended using the relations of Grynning et al. [1987] to incorporate stable conditions. The dimensions increase as conditions change from unstable to stable (Figure 2).

Combining the source area calculations with a surface description data base and a data accessing system allows a parameter to be assessed in response to different source areas shapes as meteorological conditions and scenarios change. Surface data for $100 \times 100 \mathrm{~m}$ squares were collected for a $5-\mathrm{km}$ radius circle centered on the tower (i.e., approximately 8000 squares).

\subsection{Anthropogenic Heat Flux $\left(Q_{F}\right)$}

The energy released due to human activities cannot be measured directly. C.S.B. Grimmond and T.R. Oke (manuscript in preparation, 1991) present the details of the method used to determine $Q_{F}$ on an hourly basis. $Q_{F}$ can be subdivided into three components:

$$
Q_{F}=Q_{F V}+Q_{F H}+Q_{F M} \quad \mathrm{~W} \mathrm{~m}^{-2}
$$

$Q_{F V}$, the heat released by vehicles, is a function of the amount of fuel used and its energy content. It can be related to the number of vehicles traveling within the source areas, the distance they travel, the type of fuel, and their fuel efficiency. $Q_{F H}$, the heat from stationary sources (primarily buildings), is determined from an inventory of the types of consumers and their consumption patterns within the source areas. $Q_{F M}$, the heat of metabolism, is small and a function

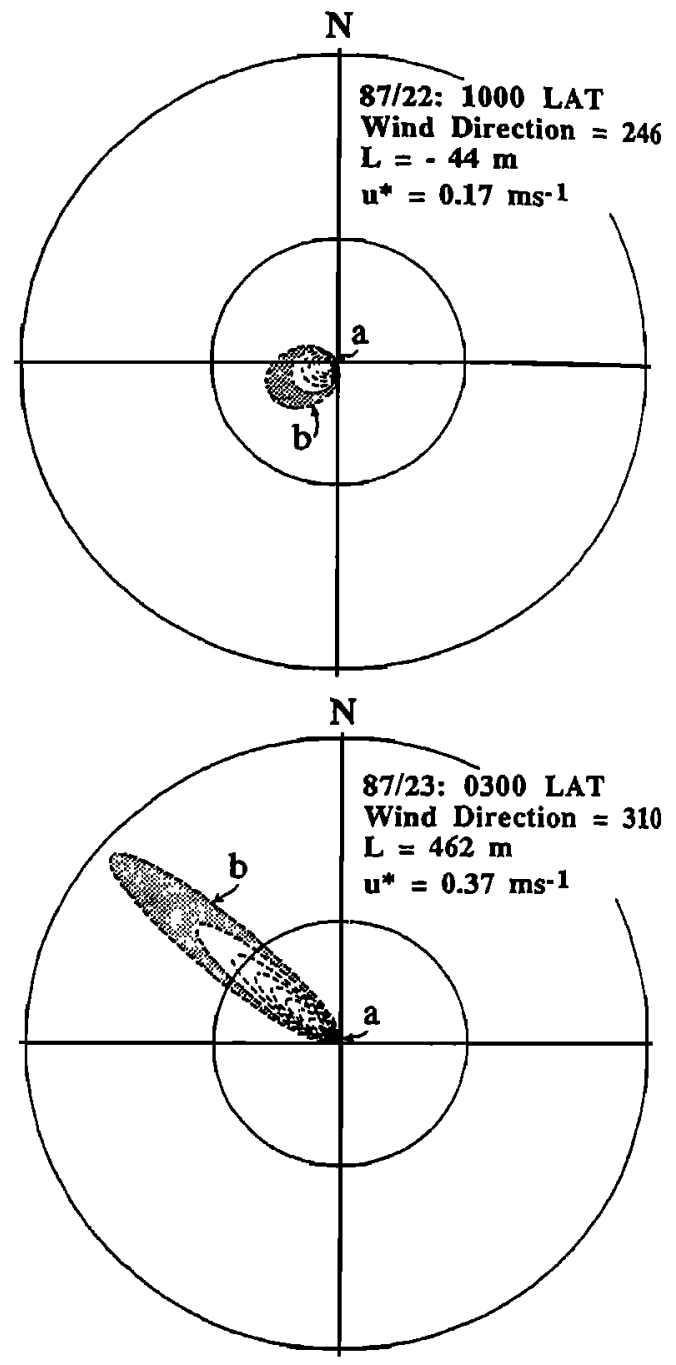

Fig. 2. Examples of the shape of the source areas calculated using the plume model. The nine weighted bands within the source area are also shown (radius of inner circle, $2 \mathrm{~km}$; radius of outer circle, $5 \mathrm{~km}$ ).

of the number of people and animals within the source areas and their metabolic rates. Hence each component requires information in the surface data base which can be accessed to fit the source area for that hour.

\subsection{Storage Heat Flux $\left(\Delta Q_{S}\right)$}

In urban areas the subsurface or storage heat flux is the net uptake or release of energy from the urban system. It includes latent and sensible heat changes in the air, build. ings, vegetation, and ground, extending from above roof level to a depth in the ground where the net heat exchange over the period of study is negligible [Oke and Cleugh, 1987]. It is not possible to directly measure the integrated heal storage of the urban system. Here the parameterization scheme of Grimmond et al. [1991] is used. The daytime storage heat flux is given:

$$
\Delta Q_{s}=a_{1} Q^{*}+a_{2} \frac{\partial Q^{*}}{\partial t}+a_{3}
$$


where $a_{1}, a_{2}$, and $a_{3}$ are empirical coefficients. The second term gives the hysteresis loop departures from the linear relationship. The empirical coefficients are derived from data for individual surface types and weighted according to their abundance in the source area. The active surface area in the source area involves determination of the plan area of green space, the three-dimensional area of buildings (roofs plus walls), and the plan area of paved surfaces. The surface coefficients are determined each hour for the appropriate source areas using the source area model and the surface data base. At night the storage heat flux is found to be approximately equal to the sum of the net all-wave radiation and anthropogenic heat flux.

\subsection{Aerodynamic Resistance $\left(r_{a}\right)$}

For a given wind speed and vapor pressure the rate of removal of water vapor depends on the atmospheric turbulence created by the wind blowing over the surface roughness elements. The integrated transfer coefficient for water vapor between the evaporating surface and some reference height in the free atmosphere is the aerodynamic resistance $\left(r_{b}\right)$ or its reciprocal the aerodynamic conductance $\left(g_{a}\right)$.

Under neutral atmospheric conditions, $r_{a}$ is determined using the logarithmic wind profile. In nonneutral conditions, and for water vapor exchange, the following expression is used [Thom, 1972]:

$$
r_{a}=\left\{\ln \left[(z-d) / z_{0}\right]-\psi\right\}\left\{\ln \left[(z-d) / z_{0_{2}}\right]-\psi_{r_{1}}\right\} /\left(k^{2} u\right)
$$

where $z$ is the height measurement $(\mathrm{m}), d$ is the displacement length $(\mathrm{m}), z_{0}$ is the momentum roughness length $(\mathrm{m}), k$ is von Kármán's constant $(0.41), u$ is the horizontal wind speed $\left(\mathrm{m} \mathrm{s}^{-1}\right.$ ); $\psi$ and $\psi_{v}$ are the stability functions for momentum exchange and water vapor, respectively, and $z_{0 v}$, the water vapor roughness length, is taken to be $0.1 z_{0}$ [Brutsaert, 1982]. For unstable conditions the stability function for momentum is [van Ulden and Holtslag, 1985]:

$\psi=2 \ln [(1+X) / 2]+\ln \left[\left(1+X^{2}\right) / 2\right]$

$$
-2 \tan ^{-1}(X)+\pi / 2
$$

where $X$ is defined by Dyer [1974] as $X=(1-16 z / L)^{0.25}, L$ is the Monin Obukhov stability length (m), and the stability function for heat and water vapor is [van Ulden and Holtslag, 1985]

$$
\psi_{H}=2 \ln \left[\left(1+y^{2}\right) / 2\right]
$$

where $y$ is defined by Dyer [1974] as $y=(1-16 z / L)^{0.25}$

For the stable case the functions of Dyer [1974] are used for heat and water vapor:

$$
\psi_{H}=-5(z-d) / L
$$

and the functions of van Ulden and Holtslag [1985] for momentum:

$$
\psi=-17\{1-\exp [-0.29(z-d) / L]\}
$$

$L$ is calculated iteratively with $u_{*}$ using Randerson [1984] when sensible heat flux data are available:

$$
L=-\left(u_{*}^{3} \rho c_{p} T_{d}\right) /\left(k g Q_{H}\right)
$$

where $g$ is acceleration due to gravity $\left(9.81 \mathrm{~m} \mathrm{~s}^{-2}\right), c_{p}$ is specific heat capacity of air at constant pressure $\left(\mathrm{J} \mathrm{kg}^{-1}\right.$ $\left.\mathrm{K}^{-1}\right), \rho$ is density $\left(\mathrm{kg} \mathrm{m}^{-3}\right)$, and $T_{d}$ is dry bulb temperature $\left({ }^{\circ} \mathrm{C}\right) . L$ is calculated using van Ulden and Holtslag [1985] when temperature differences are used:

$$
L=\left(T_{d} u_{*}^{2}\right) /\left(k g \Theta_{*}\right)
$$

where $\Theta_{*}$, the temperature scale for turbulent heat transfer, is

$$
\begin{aligned}
\Theta_{*}=(k \Delta \Theta) /\left\{\ln \left[\left(z_{2}-d\right) / z_{1}\right]-\psi_{H}\left[\left(z_{2}-d\right) / L\right]\right. \\
\left.+\psi_{H}\left[\left(z_{1}-d\right) / L\right]\right\}
\end{aligned}
$$

$\Delta \Theta$ is the potential temperature difference [McIntosh and Thom, 1972]

$$
\Delta \Theta=\Delta T(100 / p)^{K}
$$

$K=R / c_{p}, R$ is the gas constant of dry air $\left(287.04 \mathrm{~J} \mathrm{~kg}^{-1}\right.$ $\mathrm{K}^{-1}$ ), and $p$ is pressure (Pa). Here $u_{*}$ is calculated using $V a n$ Ulden and Holtslag [1985]:

$$
\begin{aligned}
u_{*}=\left[k u\left(z_{3}-d\right)\right] /\left\{\ln \left[\left(z_{3}-d\right) / z_{0}\right]-\psi\left[\left(z_{3}-d\right) / L\right]\right. & \\
& \left.+\psi\left(z_{0} / L\right)\right\}
\end{aligned}
$$

where $u\left(z_{3}\right)$ is the wind speed at the height of the anemometer $\left(\mathrm{m} \mathrm{s}^{-1}\right)$. When information to calculate the stability correction is not available, the neutral form of $r_{a}$ is used. This has been found satisfactory over forests [Shuttleworth, 1989].

\subsection{Surface Resistance $\left(r_{S}\right)$}

When there is no rain or dew on vegetation, water loss occurs through the stoma. This process is biologically controlled and changes with micrometeorological conditions. The biophysical and biochemical mechanisms of stomatal resistance $\left(r_{S T}\right)$ are poorly understood [Shuttleworth, 1989]. The form of stomatal response is qualitatively similar from one species to the next but exhibits marked variations in quantitative terms both between and within species [Jarvis et al., 1976]. At the whole canopy scale, Shuttleworth [1976, $1978,1979]$ shows that the bulk stomatal resistance is closely related to the surface resistance $\left(r_{S}\right)$, as defined by Monteith [1965]. In this approach the complex array of $r_{S T}$ for the individual leaves is replaced by an equivalent system containing a single hypothetical leaf with a single $r_{\mathrm{s}}$. Thom [1972] showed that if the source of evaporation is a forest canopy, and the aerodynamic resistance correctly describes the transfer of water, then $r_{S}$ is equivalent to the bulk $r_{S T}$. In the more general case where some of the water vapor comes from other layers (e.g., litter or understory), changes in $r_{S}$ also reflect changes in their rates of evaporation [Stewart, 1988]. In urban areas the diversity of vegetation makes the determination of a bulk stomatal resistance virtually impossible because of sampling problems and the added complication posed by the nonvegetated areas. Here $r_{s}$ is modeled as a single integrated resistance for the whole system.

At present there is insufficient knowledge to interpret the effects of environmental variables on $r_{S T}$ using a mechanistic model [Stewart, 1988], but a physically based model proposed by Jarvis [1976] can be used to predict $r_{S T}$ from empirical relationships between $r_{S T}$ and controlling environ- 
mental variables. This form of model is promising for use in urban areas. It has the advantage of being dynamically responsive to both meteorological and seasonal conditions.

The general form of whole-canopy models for forests [e.g., Lindroth, 1985; Gash et al., 1989; Sellers et al., 1986; Shuttleworth, 1988, 1989; Stewart, 1988], expressed as a conductance, $\left(g_{S}\right)$ is

$$
g_{S}=G_{1} L g(\text { variables })
$$

where $G_{1}$ is the maximum value of the surface conductance $\left(\mathrm{m} \mathrm{s}^{-1}\right), L$ is the leaf area index (LAI), and $g$ (variables) are the functions of the environmental variables which have values between zero and unity.

This general form was used to develop a model for the Sunset study site. It assumes that surface conductance is a function of the nonsynergistic interaction between stomatal aperture, LAI, and environmental variables. It operates on an hourly time scale. The environmental variables identified by Jarvis [1976] were not available and were replaced by closely related ones: quantum flux density was replaced with net radiation $\left(Q^{*}\right)$, leaf-air specific humidity was replaced with specific humidity deficit $(\delta q)$ [c.f. Stewart, 1988], leaf temperature was replaced by air temperature $(T)$, and leaf water status was replaced by soil moisture deficit $(\delta \theta)$, so that

$$
g_{S}=G_{1} g\left(Q^{*}\right) g(\delta q) g(T) g(\delta \theta) g(L)
$$

The dependence on $Q^{*}$ is expressed using the same mathematical form of equation used for solar radiation [e.g., Shuttleworth, 1989]:

$$
g\left(Q^{*}\right)=\left[Q m /\left(G_{2}+Q^{*}\right)\right] /\left[Q m /\left(Q m+G_{2}\right)\right]
$$

where $Q m$ is the annual maximum hourly net radiation (W $\left.\mathrm{m}^{-2}\right)$, and $\mathrm{G}_{2}$ is a fitted parameter $\left(\mathrm{W} \mathrm{m} \mathrm{m}^{-2}\right)$. The dependence on $\delta q$ is expressed as [Gash et al., 1989; Stewart, 1988]

$$
\begin{array}{cc}
g(\delta q)=1-G_{3} \delta q & 0<\delta q<G_{4} \\
g(\delta q)=1-G_{3} G_{4} & \delta q \geq G_{4}
\end{array}
$$

The dependence on $T$ is given [Stewart, 1988]:

$$
g(T)=\left(T-T_{L}\right)\left(T_{H}-T\right)^{T c} /\left[\left(T-T_{L}\right)\left(T_{H}-T\right)^{T c}\right]
$$

where

$$
T_{c}=\left(T_{H}-G_{5}\right) /\left(G_{5}-T_{L}\right)
$$

and $T_{L}$ and $T_{H}$ are minimum and maximum temperature limits $\left({ }^{\circ} \mathrm{C}\right)$. The dependence on $\delta \theta$ is described by [Stewart, 1988]

$$
g(\delta \theta)=1-\exp \left\{G_{6}\left[\delta \theta-\left(S_{1} / G_{6}+S_{2}\right)\right]\right\}
$$

where $S_{1}$ and $S_{2}$ are fitted parameters which relate to the maximum $\delta \theta$. The dependence on LAI follows Dolman et al. [1988] but allows for the greater diversity of vegetation found in a suburban area compared to a temperate forest:

$$
\left.g(L)=\left[\left(L A_{U}\right) / L m\right)+A_{I}\right] /\left(A_{U}+A_{I}\right)
$$

where $A_{U}$ is the area unirrigated $\left(\mathrm{m}^{2}\right), L m$ is the maximum leaf area index in $A_{U}$, and $A_{I}$ is the area irrigated $\left(\mathrm{m}^{2}\right)$.

The values of the parameters $\left(G_{1}-G_{6}\right)$ for the study area were optimized using nonlinear least squares regression
[Denis et al., 1981; Gay, 1983; Moore, 1986] between "megsured" values of $r_{S}$ and the selected environmental variables. "Measured" surface resistance $\left(r_{S}\right)$ is determined when the surface is dry by rearranging the Penman-Monteith equation and using measured $Q_{E}$ and $\beta$ [Monteith, 1965]

$$
r_{S}=\left(\frac{s \beta}{\gamma}-1\right) r_{a}+\frac{C_{a} V}{\gamma Q_{E}}
$$

\subsection{Drainage (D)}

Determination of the drainage rate for urban areas is a problem because it does not correlate directly with urban runoff. It has to be envisaged as that loss from the "storage layer" which is no longer available for evaporation, for example, the water may enter a pipe system or infiltrate into the soil. Given the range of vegetation and other surface types in urban areas, the measurement of the drainage rate involves a vast sampling problem. Even in forest areas there is a significant error involved in the measurement of this term [Shuttleworth, 1989].

The urban drainage function developed here describes the rate at which water drains from a single-layer moisture store (Figure 1) and is set proportional to the current water status of the store. The original Rutter et al. [1971, 1975] formulation had the inherent difficulty of predicting a finite drainage when the canopy is dry [Calder, 1977]. It has been rewritten [e.g., Halldin et al., 1979] to rectify this so that it reads

$$
D=D_{0} \exp [(b C)-1]
$$

where $D_{0}$ is the drainage rate when $C=S, b$ is an empirical coefficient, and $S$ is the amount of water the canopy retains after the rainfall and throughfall cease (the storage capacity). This equation is used in the model for the proportion of the source area which is vegetated but not irrigated.

For the impervious area, values from the urban runoff literature are used. They usually relate to the runoff from a single surface type rather than a land use area. Falk and Niemczynowicz [1978] propose the following equations for the relationship between drainage and storage:

$$
\begin{gathered}
D=D_{0}\left(C_{t-1}-S\right)^{b} \\
D=D_{0}\left(C_{t-1}\right)^{b}
\end{gathered}
$$

Equation (6) allows no drainage when $C<S$. This assumption has also been used in forested areas, for example by Gash and Morton [1978] and Mulder [1985]. Pratt et al. [1984] suggest that the rate of drainage from flat roofs can be assumed to be the same as paved surfaces of $1 \%$ slope. Equation (7) is used for the paved, built surfaces and for irrigated grass. The values of the coefficients for (5)-(7) are taken from Calder and Wright [1985] and Falk and Niemczynowicz [1978] and are listed in Table 2.

\subsection{Storage Capacity (S)}

The values of the surface storage capacity, like the drainage functions, are based on values taken from the literature (Table 2). The capacity for a surface type is assumed to be constant through time for all types except deciduous vegetation, where allowance is made for seasonal change. The values used are as follows: paved surfaces, $0.48 \mathrm{~mm}$ [Falk and Niemczynowicz, 1978]; roofs, $0.25 \mathrm{~mm}$ [Davies and 
TABLE 2. Values Assigned to Parameters for the "Base"' Run of the model in Vancouver, 1987

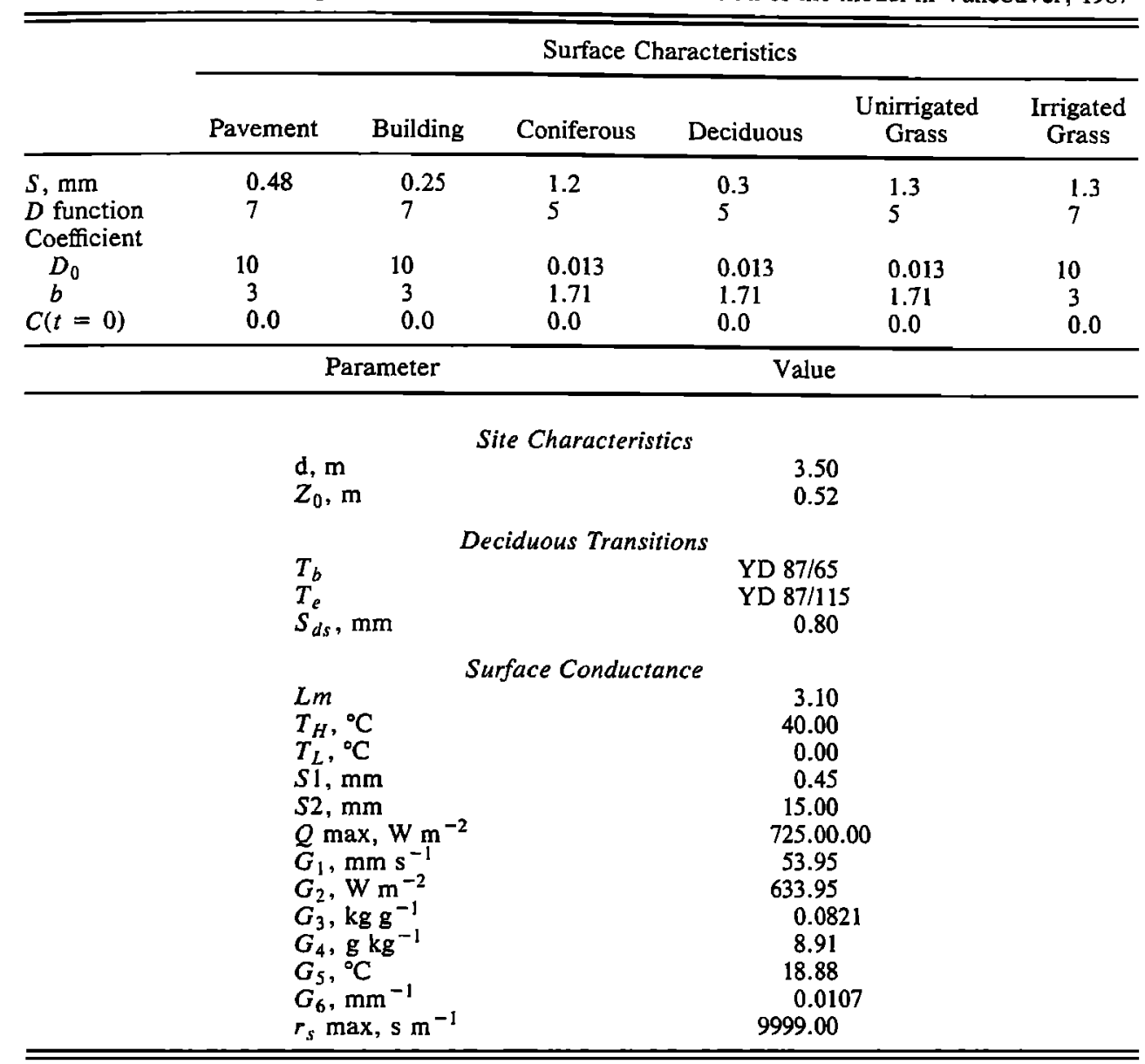

Hollis, 1982]; coniferous trees, $1.2 \mathrm{~mm}$ [Shuttleworth, 1989]; deciduous trees when leafless, $0.3 \mathrm{~mm}$; deciduous trees when in leaf, $0.8 \mathrm{~mm}$ [Shuttleworth, 1989]; and grass, $1.3 \mathrm{~mm}$ [Zinke, 1967].

\section{Field Measurements}

In order to test the evapotranspiration model and its submodels, data were collected in the Sunset suburb of Vancouver, B.C. ( $\left.49^{\circ} 15^{\prime} \mathrm{N}, 123^{\circ} 18^{\prime} \mathrm{W}\right)$ (Figure 3). The city is situated at the west end of the Lower Fraser Valley and has low to moderate relief. The Sunset area has predominantly one- and two-story single family dwellings and slopes slightly southwest toward the Fraser River.

The objective was to determine spatially averaged fluxes from an area of suburban land use at the local scale [Oke, 1984], rather than from individual surfaces such as lawn or pavement. Therefore measurements were conducted from a tower well above the height of the roughness elements to ensure that observations were conducted in the surface layer. On the basis of the results of Roth et al. [1989] all sensors were mounted at heights $>20 \mathrm{~m}$ above zero-plane displacement, and the averaging time was $60 \mathrm{~min}$.

The environmental variables measured were net radiation flux density (with a net pyrradiometer), sensible heat flux density (with a sonic anemometer-thermometer), wind speed and direction, wet- and dry-bulb air temperature (see below), relative humidity, surface wetness (see below), precipita- tion, and soil moisture deficit (see below). Full details of the measurements are available from Grimmond [1988]. All times referred to are local apparent time (LAT) (plus 0800 UT) and year day (YD).

The reversing temperature difference measurement system used to determine $\beta$, was similar to that described by McCaughey et al. [1987]. The wet- and dry-bulb thermocouples (10 junction copper/constantan thermopiles) were mounted within shields on two carts which move up and down on a trackway. The carts, separated by $7.1 \mathrm{~m}$, are reversed twice each hour. A ten-min period allows for travel and equilibration at the new level. The remaining $20 \mathrm{~min}$ at each level allowed for two 10-min averages.

The surface wetness sensors followed the design of Weiss and Lukens [1981]. The sensors consist of a frame $(0.1 \times 0.1$ m) with 30 AWG wire threaded across the center and muslin material weaved through the wire. The wire has $2 \mathrm{~V}$ ac passed through it, and the output voltage varies depending on the wetness of the material (a surrogate for the surface). The output does not give a numerical value of degree of wetness but an indication of whether the surface is wet or dry. Two such sensors were located on unirrigated grass and a third in a coniferous hedge, starting on YD 87/38. Visual observations of the drying of different types were also made throughout the measurement period.

Gravimetric soil moisture samples were taken approximately three times a week from two sites near the tower. 


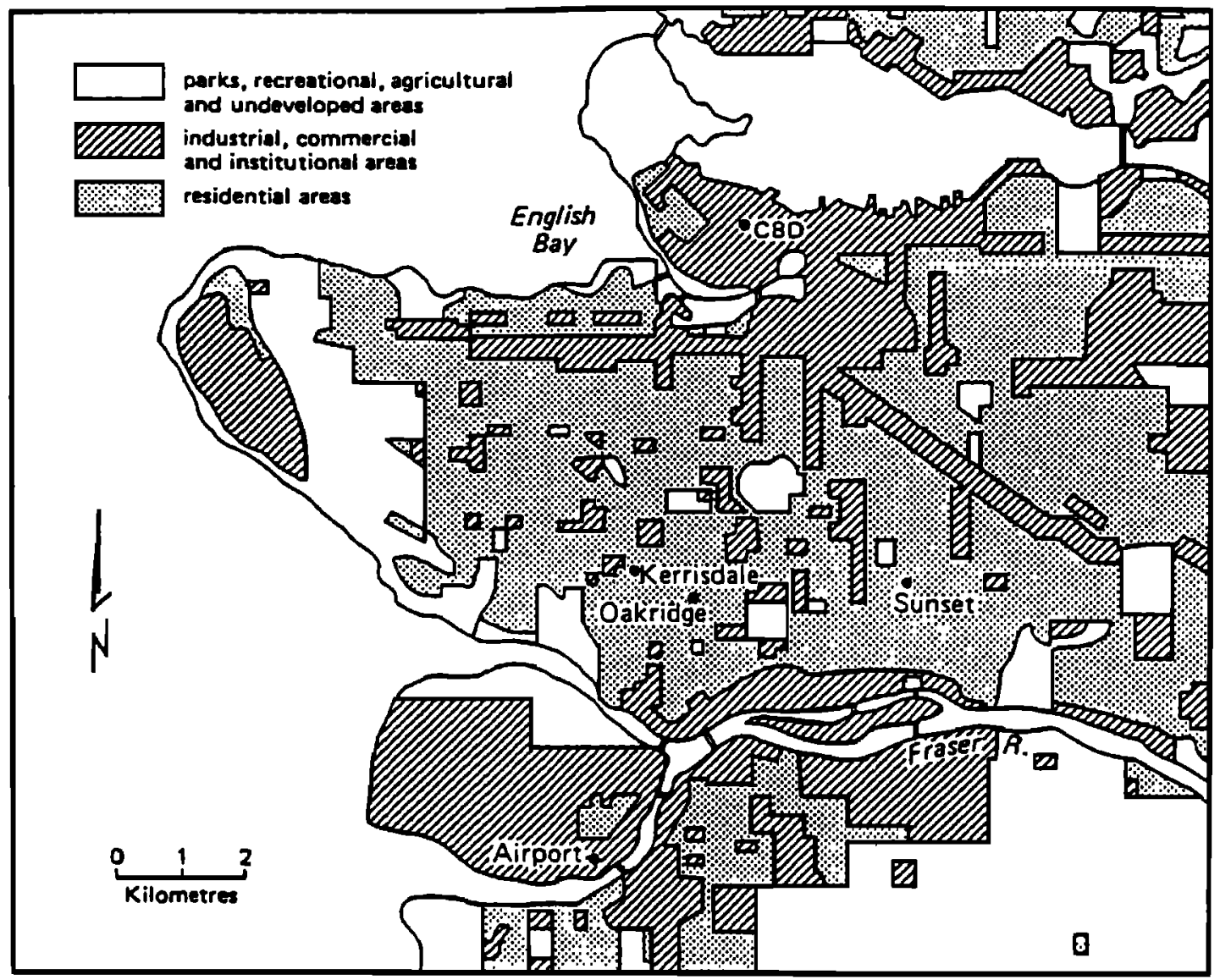

Fig. 3. The location of the Sunset study site in the Vancouver area and the surrounding land uses.

From mid-May (YD 87/133), samples were gathered at an additional three sites, both irrigated and nonirrigated, around the tower area. The average dry weight moisture content for the profile from the surface to a depth of $200 \mathrm{~mm}$ was determined and used with dry bulk density measurements to determine soil moisture deficit.

Water use was monitored from YD 87/139 by the Engineering Department, City of Vancouver, in the nearby residential area of Oakridge (Figure 3). The water use for the 21-ha catchment was recorded at 15 -min intervals with a resolution of $2.832 \mathrm{~m}^{3}$. The external water use (i.e., mainly for irrigation) was separated from the total use on the basis of experience in the same catchment [Grimmond and Oke, 1986]. It was assumed that the same depth of water was applied to the irrigated area in the Sunset suburb as was applied in the Oakridge catchment. From visual surveys at both sites it was determined that different proportions of the residential vegetation were irrigated (Oakridge, 95\%; Sunset, $60 \%$ ). The external water use data set was extended back to YD $87 / 121$, selected as the day of the onset of irrigation (based on observations and Grimmond [1983]), by using a multiple regression equation developed from the hourly 1987 data set incorporating time of day, hours since rain, available energy, temperature, and vapor pressure deficit.

\section{Development of the Surface Conductance SUbMOdel}

Figure 4 shows the ensemble mean and standard deviation of $g_{S}$ at the Sunset suburban site for 543 hours. The diurnal trend is similar to that reported for forests [e.g., Shuttleworth, 1989], but the values are approximately $75 \%$ smaller and have approximately double the hourly standard deviation [e.g., Stewart and de Bruin, 1984; Shuttleworth, 1988: Stewart, 1988]. The smaller size of $g_{S}$ in urban areas is undoubtedly due to the presence of nonvegetated surfaces.

The surface resistance submodel was developed and tested using data for 543 daylight hours when the surface was dry. To be dry, a surface must meet the following criteria [Shuttleworth, 1988]: rain is not recorded in the current of previous 3 hours; 3 hours with positive $Q^{*}$ have occurred since rainfall; the hour preceding recorded rain was regarded as not dry; in the morning, 2 hours have elapsed since $Q^{*}$ first became positive; the wetness sensors record the surface as dry; and there are no visible puddles or other traces of rain.

To develop and test the model, the Sunset data set was split into two independent sets by arbitrarily putting alternate days into separate sets: one of 300 hours (AD1) and the other of 243 hours (AD2). This approach was adopted because no independent data set exists for a suburban area 


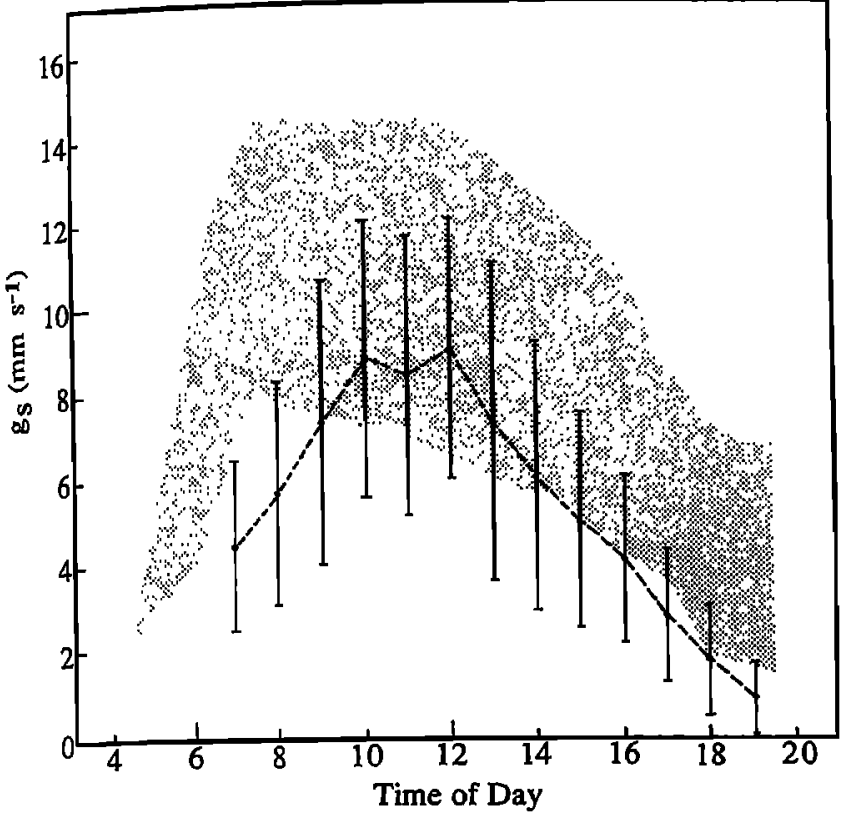

Fig. 4. Diurnal trend of ensemble mean and standard deviation of measured surface conductance for Sunset suburban site, Vancouver, British Columbia, for dry, daylight hours. The shaded area shows the range of values from eight forests [from Shuttleworth, 1989, Figure 10].

which covers a sufficiently wide range of conditions.

The environmental variables controlling conductance were determined as follows. $Q^{*}$ and $T$ were measured directly, $\delta q$ was calculated from measured $T$ and pressure $p$. $\delta \theta$ was determined for unirrigated areas using profiles of gravimetric soil moisture and the dry bulk density of the soil. Irrigated areas were found to have no $\delta \theta$ at any time. The surface description data base and the source area model enabled the areas with coniferous, deciduous, and irrigated and unirrigated grass to be identified for each hour. Thus an areally weighted $\delta \theta$ was determined for each hour. It was assumed that all of the irrigated area is grass and that mowing keeps the LAI of the grass constant at 1.6 [Ripley and Redmann, 1975].

The LAI for the unirrigated area was determined as an areally weighted average of the coniferous, deciduous, and grass values for each hour. The LAI of coniferous and deciduous vegetation were set to lie in the ranges of 4-6 and 0-4, respectively [Kramer and Kozlowski, 1979]. A full circle panorama of photographs was taken from the tower weekly to identify the stages of the growing season. They were used to model LAI for each day for the two vegetation types using [Street and Opik, 1984]

$$
\log \frac{L+1}{a-(L+1)}=k\left[\left(d-d_{0}\right)-\left(d_{1}-d_{0}\right)\right]
$$

where $a$ is the maximum LAI minus the winter minimum, $\mathrm{k}$ is a fitted parameter $(0.05), d$ is the day of interest, $d_{0}$ is the starting day of the curve from winter minimum of LAI (YD $87 / 45$ ), and $d_{1}$ is the day of inflection of the $S$ curve (YD $87 / 95$ ). It was possible to assign a daily value of LAI for each vegetation type and, depending on the source area being sampled, to determine the weighted average of LAI for each hour. The proportion of the source area irrigated was determined from visual surveys and water use data in conjunction with the data base and the source area model.

The other model parameters were assigned as follows: maximum areally weighted $L m$ is 3.1 , based on the calculated LAI; $Q m$ was set to $725 \mathrm{~W} \mathrm{~m}^{-2}$ using measured $Q^{*}$ during June; $T_{H}$ was set to $40^{\circ} \mathrm{C}$ and $T_{L}$ to $0^{\circ} \mathrm{C}$ following Stewart [1988] and Gash et al. [1989]; and $S_{1}$ and $S_{2}$ were

TABLE 3. Fitted Parameters and Test Statistics for the Surface Resistance Model

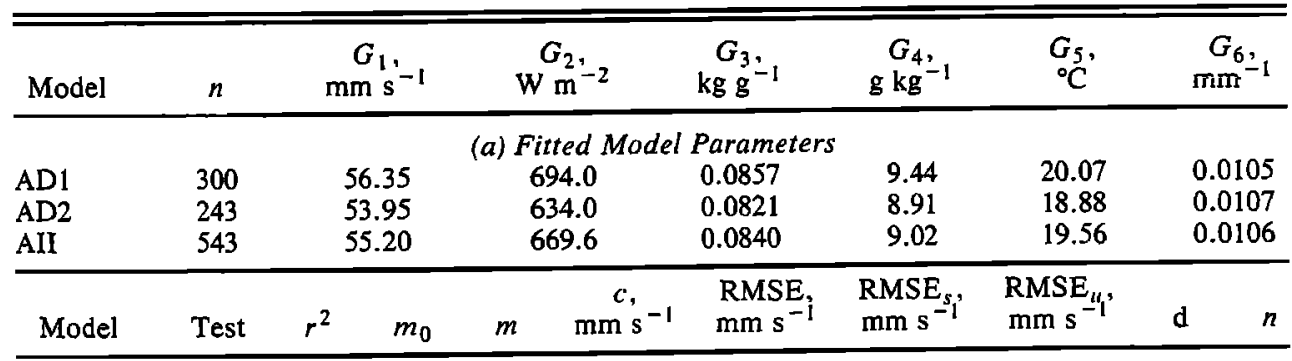

(b) Model Development Statistics

\begin{tabular}{|c|c|c|c|c|c|c|c|c|c|c|}
\hline \multirow[b]{2}{*}{ AD 1} & \\
\hline & AD 1 & 0.61 & 0.90 & 0.62 & 2.37 & 2.35 & 1.45 & 1.85 & 0.87 & \\
\hline $\mathrm{AD} 2$ & $\mathrm{AD} 2$ & 0.71 & 0.93 & 0.73 & 1.47 & 1.75 & 0.88 & 1.52 & 0.91 & \\
\hline AII & AII & 0.65 & 0.91 & 0.66 & 1.99 & 2.11 & 1.21 & 1.73 & 0.89 & \\
\hline \multicolumn{11}{|c|}{ (c) Model Test Statistics } \\
\hline$A D 1$ & $\mathrm{AD} 2$ & 0.71 & 0.89 & 0.74 & 1.20 & 1.79 & 0.91 & 1.54 & 0.91 & \\
\hline $\mathrm{AD} 2$ & $\mathrm{AD} 1$ & 0.61 & 0.92 & 0.61 & 2.60 & 2.36 & 1.47 & 1.85 & 0.87 & \\
\hline \multicolumn{11}{|c|}{ May-June } \\
\hline AD 1 & AD 2 & 0.72 & 0.89 & 0.74 & 1.14 & 1.75 & 0.89 & 1.50 & 0.91 & 184 \\
\hline AD 2 & AD 1 & 0.65 & 0.92 & 0.65 & 2.49 & 2.26 & 1.38 & 1.79 & 0.88 & 202 \\
\hline
\end{tabular}

Statistics are $n$, number of hours; $m_{0}$, slope forced through the origin; $m$ and $c$, slope and intercept for ordinary linear regression; RMSE, root-mean-square error; $\mathrm{RMSE}_{s}$ systematic error; RMSE ${ }_{u}$, unsystematic error; $d$, index of agreement [Willmott, 1984]. 


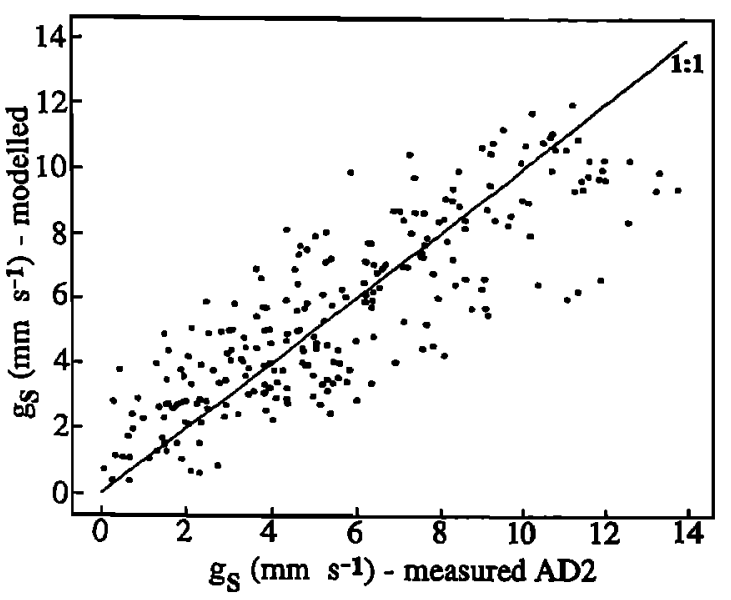

Fig. 5. Comparison between hourly measured and modeled surface conductance using data set AD2 for modeled AD1.

determined by trial and error [Dolman et al., 1988] to be 0.45 and $15 \mathrm{~mm}$, respectively.

Table 3 lists the fitted parameters and the test statistics for the separate and combined data sets. The values of the model parameters $G_{3}$ to $G_{6}$ are similar to those reported by Stewart [1988] and Gash et al. [1989] for temperate forests (Thetford, U.K., and Les Landes, France, respectively). $G_{1}$ and $G_{2}$ are not the same as those of these forested sites. This is expected for $G_{1}$ because the urban canopy vegetation is more heterogeneous and sparse. Second, $G_{2}$ is associated with net all-wave radiation in this study rather than net solar radiation, as in the other studies. This is the best form of the model after several attempts to incorporate urban features.

The statistics pertaining to model development and performance are presented in Tables $3 b$ and $3 c$, respectively, and in Figure 5 . The model was first developed using data set $\mathrm{AD} 2$ and tested against AD1, then the process was reversed. The $r^{2}$ of 0.71 for model AD2 is similar to that reported by Stewart [1988]. AD1 always gave a lower degree of explanation. This is attributed to a greater number of outliers associated with cloudy and partly cloudy hours, suggesting that the net radiation function is inadequate for such conditions. All three models show larger unsystematic than sys-

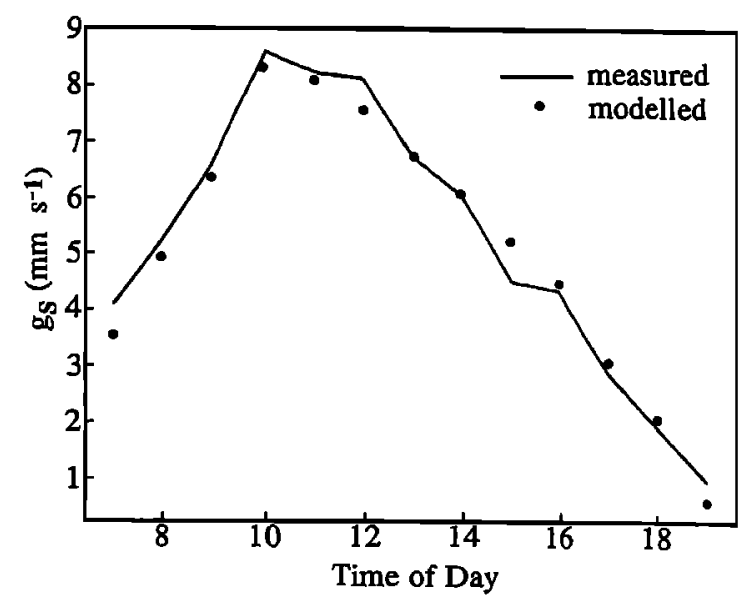

Fig. 6. Ensemble mean of measured and modeled surface conductance using data set AD2 for modeled AD1.
TABLE 4. Statistics for the Comparison Between Measured and Modeled (Using "Base" Values) $Q_{E}$ for Vancouver, British Columbia

\begin{tabular}{|c|c|c|}
\hline Statistic & Hourly & Daily \\
\hline \multicolumn{3}{|l|}{ Mean, $\mathrm{W} \mathrm{m}^{-2}$} \\
\hline Measured & 40.10 & 40.49 \\
\hline \multirow{2}{*}{\multicolumn{3}{|c|}{ Standard deviation $\mathrm{W} \mathrm{m}^{-2}$}} \\
\hline & & \\
\hline Measured & 63.03 & 21.80 \\
\hline Modeled & 58.20 & 23.87 \\
\hline$m$ & 0.83 & 0.93 \\
\hline$r^{2}$ & 0.81 & 0.71 \\
\hline$d$ & 0.95 & 0.91 \\
\hline$N \& S^{*}$ & 0.81 & 0.64 \\
\hline RMSE, $\mathrm{W} \mathrm{m}^{-2}$ & 27.65 & 13.00 \\
\hline $\operatorname{RMSE}_{s}, \mathrm{~W} \mathrm{~m}^{-2}$ & 10.72 & 2.17 \\
\hline $\operatorname{RMSE}_{a}, \mathrm{~W} \mathrm{~m}^{-2}$ & 25.49 & 12.82 \\
\hline
\end{tabular}

*Nash and Sutcliffe [1970] goodness of fit.

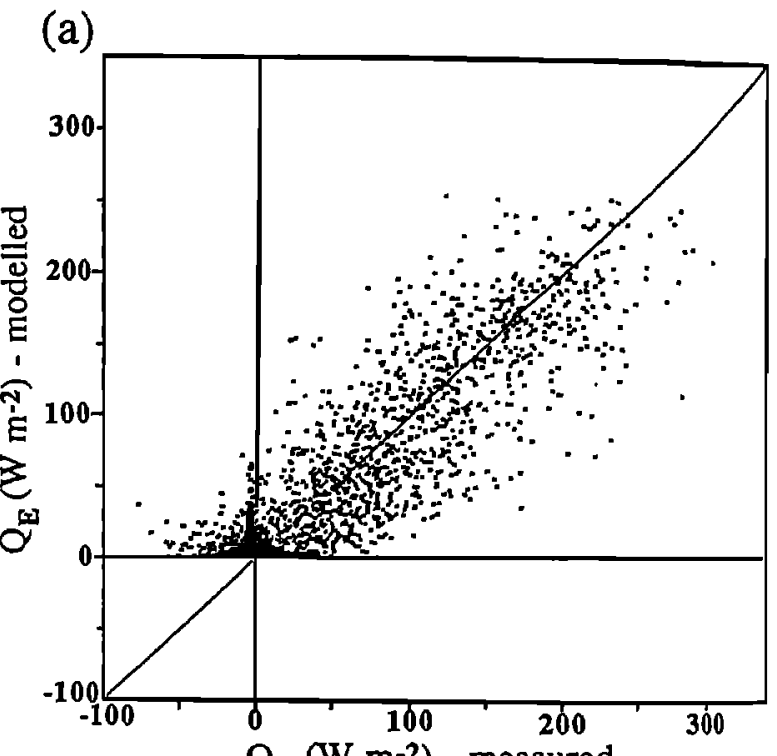

(b)

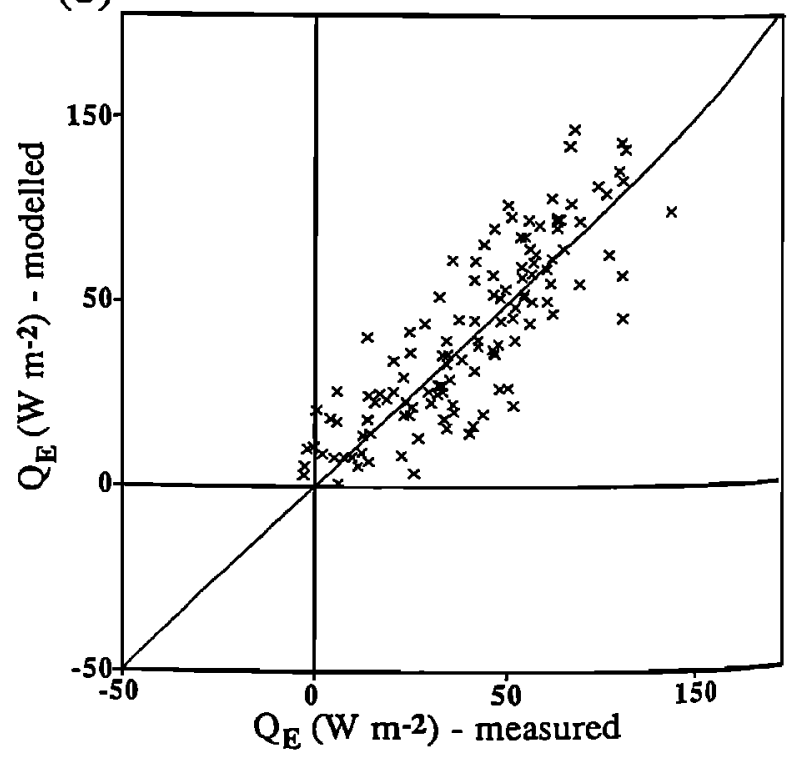

Fig. 7. Comparison of measured and modeled $Q_{E}$ for the "base" model run for Vancouver, British Columbia: (a) hourly (b) daily. 
tematic errors, which indicates there is only a small bias in the model estimates. The slope of the best fit line indicates an overprediction for low $g_{S}$ (high $r_{S}$ ) and an underprediction for high $g_{S}$ (low $r_{S}$ ). The slopes forced through the origin (Table $3 c$ ) are similar to those obtained by Stewart [1988]. Figure 6 shows the diurnal trend of the ensemble mean measured and modeled $g_{S}$. The modeled and measured data exhibited the same trend using either model. In both cases the model underpredicts in the morning.

The AD1 model was selected to calculate $r_{S}$ in the evapotranspiration-interception model because it has the lowest root-mean-square error (RMSE), and the slope of the line (m) is the closest to unity.

\section{Performance of the Urban EVAPOTRANSPIRATION MODEL}

\subsection{Methods Used to Assess the Performance of the Model}

The model was initialized, with the surface dry, on February 3 (YD 87/33) at 0000 LAT and terminated on June 28 (YD 87/179) at 0800 LAT, when field measurements ceased. During this 3513-hour period, $Q_{E}$ was modeled continuously, and there are 2944 hours of measured data available for comparison.

The performance of the model is evaluated at a number of temporal scales: (1) hourly, each hour with both measured and modeled flux data, (2) daily, fluxes for all hours, when both measured and modeled data are available on a day, are averaged and compared, because of missing data a "day" does not necessarily consist of 24 hours, (3) cumulative hourly, hours when both measured and modeled data are accumulated and compared (because of missing data the values are less than the "true" total $E$ for the time period (YD 87/33-179)), and (4) ensemble hourly, for each month and for the whole time period (YD 87/133-179) the values for a particular hour are averaged. The modeled surface water state was also compared with that from two wetness sensors.

\section{2. "Base" Run of the Model}

For the "base" run of the model the values assigned to the various parameters were chosen to be the most physically realistic (Table 3). They are not a best fit to the model.

The statistics of the model's performance as compared to the measured $Q_{E}$ are presented on an hourly and daily basis in Table 4 . The results for the model are better on an hourly than a daily basis primarily because of the large number of hourly data points (Figures $7 a$ and $7 b$ ). In both figures the data are distributed around the one to one line, and the hourly RMSE of $27.7 \mathrm{~W} \mathrm{~m}^{-2}$ is of the same order as the error of the measurements. The cumulative $E$ for the measurement period (Figure 8) shows that the model underpredicts up to about YD 87/65, overpredicts between YD 87/140-160, and matches for the remainder of the period.

Figure 9 shows the time series of measured and modeled $Q_{E}$ for two periods. In the early part of the year the model underpredicts during the middle of the day (Figure $9 a$ ). From about YD 87/75 the model mimics the measured data extremely well under all conditions except during dewfall (Figure $9 b$ ).

Figure 10 provides a means to compare the modeled surface state with that recorded by the wetness sensors. In

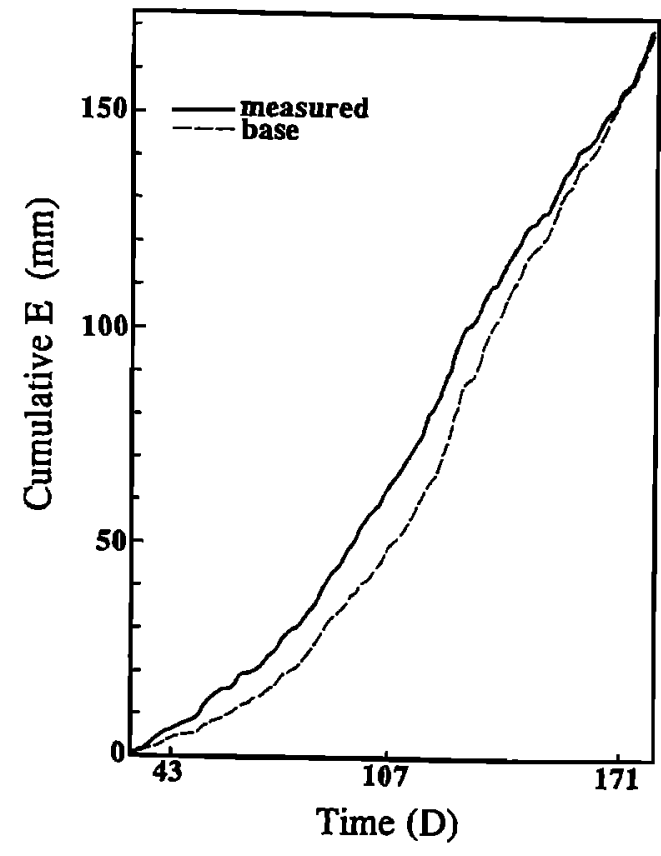

Fig. 8. Cumulative measured and modeled ("base" run) evaporation for Vancouver, British Columbia.

each box of five traces the upper two plots show the water arriving at the surface; at the top is the rainfall received by all surfaces, and the second is the external water use $(w u)$ which is only received by the irrigated grass portion of the
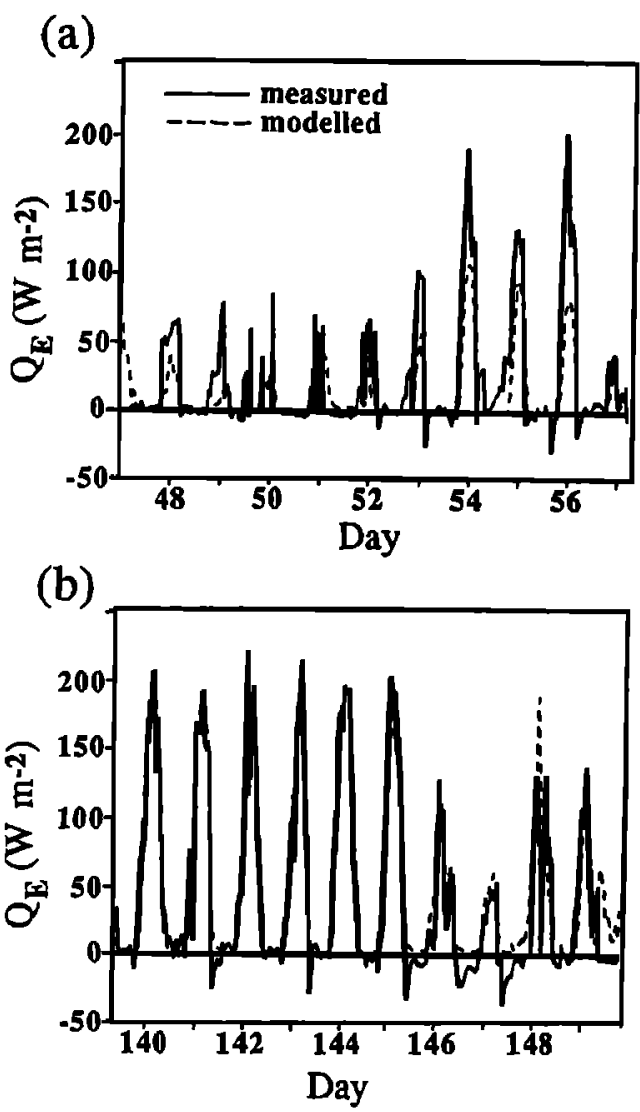

Fig. 9. Time series of hourly measured and modeled $Q_{E}$ ("base") for Vancouver, British Columbia. Note that the measured data are not continuous (a) YD 87/47-57 (b) YD 87/140-150. 
(a)

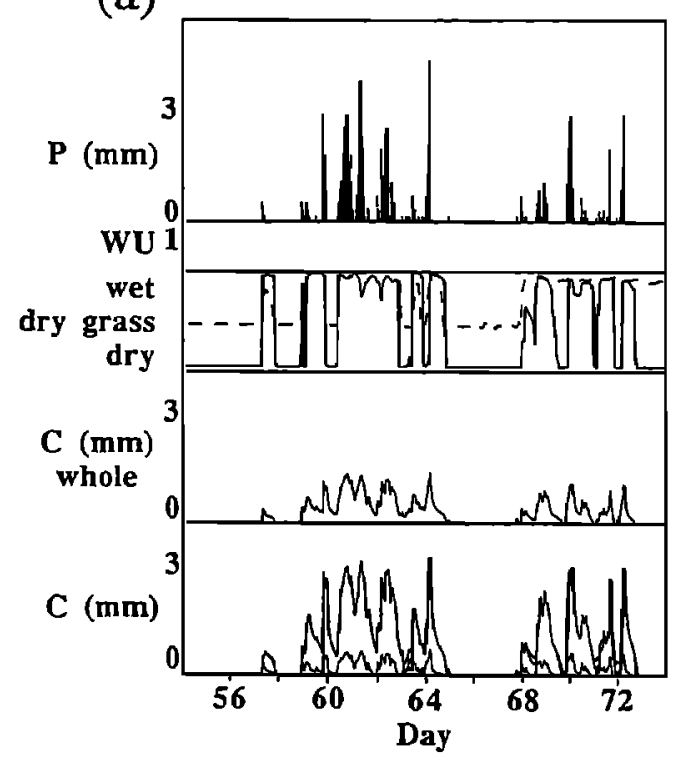

(b)

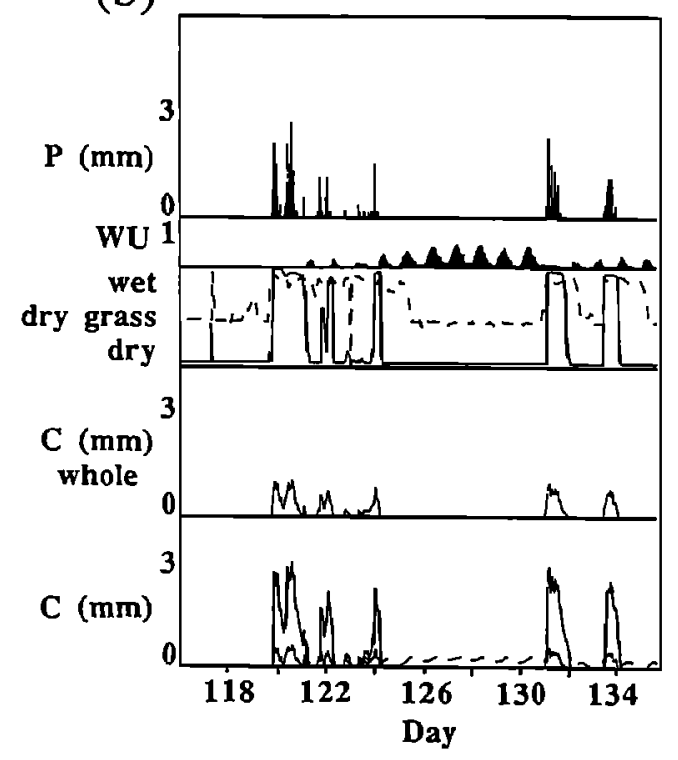

Fig. 10. Time series of hourly precipitation, water use, surface water use, surface wetness, and modeled surface water state for Vancouver, British Columbia (see text for details) (a) YD 87/54-74 (b) YD 87/116-136.

surface. External water use did not begin until YD 87/121. The third plot shows the status of the wetness sensors (i.e., whether wet or dry). Note that the sensor located on the grass (dashed curve) has a smaller range. The fourth trace is the modeled surface water status of the whole surface, and the fifth or lowest plot shows the modeled wetness status of the individual surface types. The six individual surfaces are not separately labeled, but the vegetated surfaces are those which hold more water on the surface, and the lesser values are the built and paved surfaces. Once irrigation begins (Figure 10b), the state of the irrigated grass surface (the dashed curve in the lowest plot) becomes distinguishable from the other surfaces. In general, the model does an extremely good job of indicating when the surface is dry. Visual observations indicate that the paved and built surfaces dry more quickly than the vegetated surfaces, and as
Figure 10 shows, the modeled paved and built surfaces mimic this pattern. This suggests that the drainage functions in the evaporation model simulate the surface water state appropriately. The only feature not well represented is dewfall which was visible on the grass sometimes but not simulated.

\subsection{Sensitivity Analysis of the Model}

In order to assess the robustness of the model and its sensitivity to various input parameters and equations its performance was investigated when inputs were changed over a range. The effects of such changes are reported in comparison to both the measured results and the base run. Unless otherwise specified only one variable was changed from the base run (Table 3). Cumulative plots show the influence of the changes on the modeled evaporation $(E)$ and allow seasonal effects to be gauged.

6.3.1. Time step. When this type of model is used in forests, time steps of 120 [Shuttleworth, 1988], 300 [Rutter et al., 1971], and 720s [Sellers and Lockwood, 1981] have been used. These rather short time steps allow for changes in the drainage rate, surface state, and evapotranspiration rate within an hour. The "base" time step used in this study is 300 s, that is, 12 steps per hour.

Decreasing the computational interval to $120 \mathrm{~s}$ does not improve the performance of the model and extending it to $720 \mathrm{~s}$ shows slight improvement. Changing to $3600 \mathrm{~s}$ causes a further slight improvement in the statistics, but the surface dries too quickly so the surface water state shows a series of spikes rather than the more realistic gradual drying curves seen in Figure 10.

We conclude that the model can be run at the longer 720-s time step and maintain a realistic surface state, but extending to one hour results in less realistic predictions of surface water state.

6.3.2. Aerodynamic resistance $r_{a}$. The base version of the model uses the stability corrected equation for $r_{a}$. Runs made using the neutral and the Thom and Oliver [1977] equations for $r_{a}$ indicate that the model is not very sensitive to which equation is used, and $Q_{E}$ values are similar. Therefore it is not essential to have the input necessary to calculate the stability functions for the determination of $r_{a}$. In many forest evaporation-interception studies the neutral method has been used alone and found to be satisfactory [Shuttleworth, 1988].

6.3.3 Surface resistance $r_{S}$. Two types of changes affecting $r_{S}$ were run: first, alterations in $r_{S}$ maximum and second, changes to the values of the parameters within the $r_{S}$ submodel (section 3.5).

The model was run with five different methods to deal with large $r_{s}$ (or $g_{S}$ approaching zero) and negative $Q^{*}$. In the base run, when $g_{S}$ approaches zero or becomes negative, $r_{S}$ is set to $9999 \mathrm{~s} \mathrm{~m}^{-1}$. In the other four cases, $r_{s}$ was set to $9999,2500,1250$, or $750 \mathrm{~s} \mathrm{~m}^{-1}$ when $Q^{*}$ was negative. The performance statistics show little difference between the base run and those with $r_{s} \max =9999 \mathrm{~s} \mathrm{~m}^{-1}$. As the value of $r_{S} \max$ is decreased, the performance deteriorates slightly. There is a systematic influence on the cumulative flux, primarily due to the fact that as $r_{S} \max$ is reduced, nightime values of $Q_{E}$ increase, and therefore accumulated $Q_{E}$ becomes larger. However, the daytime performance is not improved. 
TABLE 5. Statistics of Model Performance for $Q_{E}$ When the Storage Capacity $(S)$ is Changed for Irrigated and Unirrigated Grass

\begin{tabular}{|c|c|c|c|c|c|}
\hline & \multicolumn{5}{|c|}{$S$ Capacity (Irrigated, Unirrigated), for Grass, $\mathrm{mm}$} \\
\hline & $0.5,0.5$ & $1.3, * 1.3$ & $6.4,6.4$ & $7.6,7.6$ & $7.6,10.2$ \\
\hline \multicolumn{6}{|c|}{ Hourly Statistics } \\
\hline Mean, $\mathrm{W} \mathrm{m}^{-2}$ & 43.08 & 40.38 & 38.03 & 37.91 & 37.87 \\
\hline $\mathrm{sd}, \mathrm{W} \mathrm{m}^{-2}$ & 59.91 & 58.20 & 56.72 & 56.65 & 56.65 \\
\hline$m$ & 0.84 & 0.83 & 0.82 & 0.82 & 0.82 \\
\hline$r^{2}$ & 0.78 & 0.81 & 0.83 & 0.83 & 0.83 \\
\hline RMSE, $W \mathrm{~m}^{-2}$ & 30.07 & 27.65 & 26.42 & 26.39 & 26.40 \\
\hline $\mathrm{RMSE}_{s}, \mathrm{~W} \mathrm{~m}^{-2}$ & 10.58 & 10.72 & 11.69 & 11.75 & 11.76 \\
\hline $\mathrm{RMSE}_{u}, \mathrm{~W} \mathrm{~m}^{-2}$ & 28.15 & 25.49 & 23.70 & 23.63 & 23.63 \\
\hline$d$ & 0.94 & 0.95 & 0.95 & 0.95 & 0.95 \\
\hline $\mathrm{N} \& \mathrm{~S} \dagger$ & 0.77 & 0.81 & 0.82 & 0.82 & 0.82 \\
\hline \multicolumn{6}{|c|}{ Daily Statistics } \\
\hline Mean, $\mathrm{W} \mathrm{m}^{-2}$ & 44.66 & 41.87 & 39.44 & 39.31 & 39.25 \\
\hline $\mathrm{sd}, \mathrm{W} \mathrm{m}^{-2}$ & 26.09 & 23.87 & 22.45 & 22.39 & 22.42 \\
\hline$m$ & 0.98 & 0.93 & 0.98 & 0.89 & 0.89 \\
\hline$r^{2}$ & 0.67 & 0.71 & 0.75 & 0.75 & 0.75 \\
\hline RMSE, $\mathrm{W} \mathrm{m}^{-2}$ & 15.60 & 13.00 & 11.58 & 11.53 & 11.52 \\
\hline $\mathrm{RMSE}_{s}, \mathrm{~W} \mathrm{~m}^{-2}$ & 4.20 & 2.17 & 2.61 & 2.69 & 2.68 \\
\hline $\operatorname{RMSE}_{u}, \mathrm{~W} \mathrm{~m}^{-2}$ & 15.02 & 12.82 & 11.28 & 11.21 & 11.21 \\
\hline$d$ & 0.89 & 0.91 & 0.93 & 0.93 & 0.93 \\
\hline N\&S & 0.49 & 0.64 & 0.72 & 0.072 & 0.72 \\
\hline
\end{tabular}

References for $S$ capacity values are as follows:

1.3, Zinke [1967];

6.4, Brater [1968], Mechler and Riecken [1977], and Nouh [1986];

7.6, Wright-McLaughlin Engineering [1969]:

10.2, Wright-McLaughlin Engineering [1969].

*Base value.

$\dagger$ Nash and Sutcliffe [1970].

The $r_{S}$ parameters $\left(G_{1}-G_{6}\right)$ were changed between the three sets of model parameters presented in Table 3 (AD2 is the base set). The base results are generally slightly better. Using $\mathrm{AD} 1$ and All parameters, the calculated daytime fluxes are slightly less than for the base case. The values obtained using $\mathrm{AD} 1$ are smaller than those using the All parameters. The AD1 and All versions of the runs remain closer to parallel with the measured cumulative $E$ during the later months.

The model responds to reasonably small changes in $r_{S}$ (as will be produced by changing $r_{s}$ model parameters), but it is not so sensitive as to make the use of any of the models in section 5 unwise.

6.3.4 Storage capacity (S). Three types of changes were made to the model relating to the storage capacity: first, changing $S$ for an individual surface while keeping the rest at the base value, second, changing all surfaces values, and third, changing $S$ in conjunction with the drainage functions. The results of the latter are discussed in section 6.3.5.

In this first test the value of $S$ for each surface type was changed over a range of values determined from previous studies. It should be appreciated that the response of the model also depends on the relative abundance of the surface type within the study area.

Paved and building: When $S$ was changed from 0.30 to $2.50 \mathrm{~mm}$ for paved and from 0.25 to $2.5 \mathrm{~mm}$ for buildings, there were only slight decreases in mean modeled values of $Q_{E}$ and its RMSE, RMSE , $_{\text {, and }} \mathrm{RMSE}_{U}$. This is reassuring because it is difficult to measure and/or assign absolute values to this parameter [see Falk and Niemczynowicz, 1978].

Trees: Changing $S$ for coniferous vegetation from 0.75 to $2.5 \mathrm{~mm}$, the size of the winter and summer values of $S$ for deciduous vegetation, and the timing of the transition between winter and summer are virtually undetectable. However, it should be noted that deciduous and coniferous vegetation occupy only a small area of the study site.

Grass: $S$ was varied over the large range from 0.5 to 10.2 $\mathrm{mm}$ that is found in the literature (Table 5). The irrigated and unirrigated grass are assigned the same value except for one case where the unirrigated is given $10.2 \mathrm{~mm}$ and the irrigated $7.6 \mathrm{~mm}$. The model shows a distinct response to the size of $S$ for grass because the changes are much larger than other surface types and because grass is the most extensive surface type in the study area. It is apparent from Figure 11 that the larger the value of $S$ the smaller the modeled $E$, down to a limit of $6.4 \mathrm{~mm}$ above which $S$ has no further influence. Once external water use begins (YD 87/121) on a portion of the grass, there is a distinct increase in the modeled values of $E$ (i.e., a steeper slope in Figure 11). The statistics show slightly contradictory effects of changing $S$ at the hourly and daily scales. With increasing $S$ the hourly statistics show a decreased slope $m$, and increased $r^{2}$, a decreased RMSE and RMSE ${ }_{U}$, but an increased RMSE . On a daily basis, however, increasing $S$ is associated with a decrease in RMSE and in both the RMSE R $_{S}$ and $\mathrm{RMSE}_{U}$. The hourly ensemble data show that the largest difference from the base results occurs at $1800 \mathrm{LAT}$. In the winter the difference at this time is $\leq 7 \mathrm{~W} \mathrm{~m}^{-2}$ for $S=0.5 \mathrm{~mm}$ and $\leq 20$ 


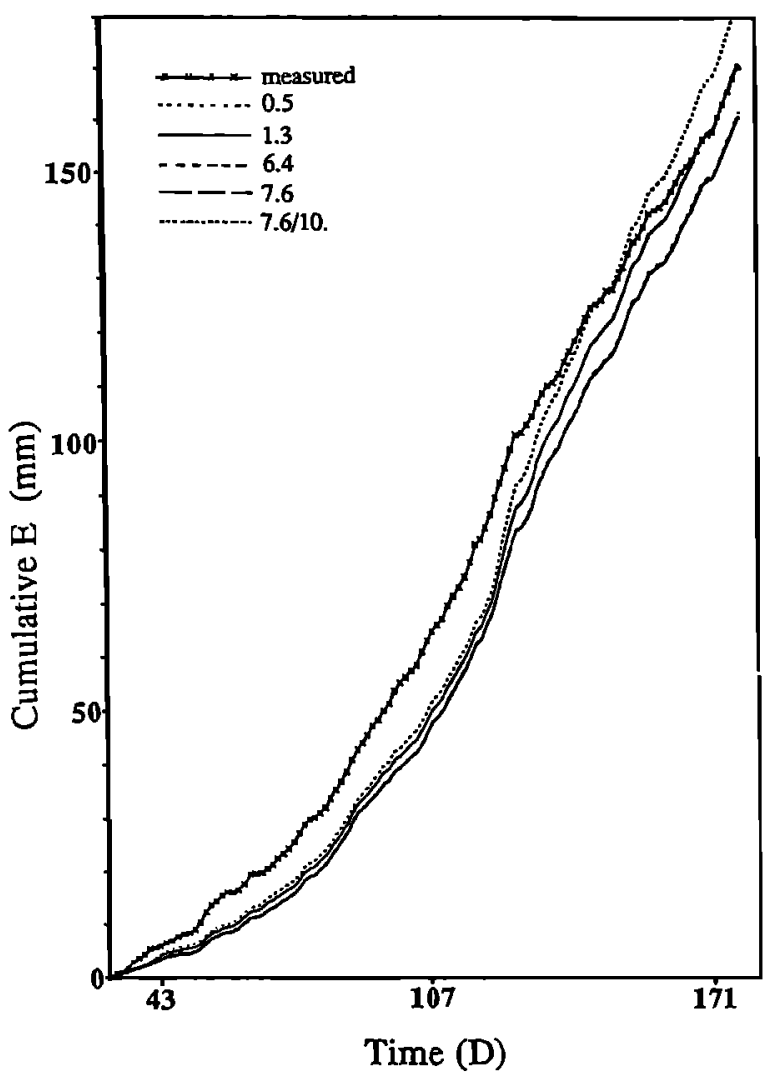

Fig. 11. Influence of the value assigned to the surface storage capacity of grass on cumulated $E$.
$\mathrm{W} \mathrm{m} \mathrm{m}^{-2}$ in June. With large values of $S$ the modeled $Q_{E}$ is reduced by $2-3 \mathrm{~W} \mathrm{~m}^{-2}$ during the winter, and in June the maximum difference is approximately $6 \mathrm{~W} \mathrm{~m}^{-2}$ in the morning and $15 \mathrm{~W} \mathrm{~m}^{-2}$ in the late afternoon. It appears from this sensitivity analysis that the size of $S$ for grass which influences the modeled $Q_{E}$ is around the value of $1.3 \mathrm{~mm}$ suggested by Zinke [1967].

In four runs all the values of $S$ for the different surfaces were changed together (see Table 6 for details): first, all values of $S$ were decreased to small values, second, all were assigned large values, third, all were set to $0.5 \mathrm{~mm}$, and fourth, all were set to $1.0 \mathrm{~mm}$. All of the runs underpredict $Q_{E}$ until the onset of irrigation, as does the base run. After that the slope of the cumulative curve steepens considerably for all runs except for the case where all $S$ values were large. After about YD 87/145 the slopes for all curves, except the base run, are similar to the measured values, suggesting they are performing well on a hour-to-hour basis. The comparison statistics suggest that when $S$ is set to larger values the model performs better (Table 6).

6.3.5 Drainage functions (D). The drainage functions were varied over a range of coefficients and equation types (see Table 7 for details). Initially, the storage capacities for all surfaces were set to one value then changed to $0.5,1.0$, and $2.0 \mathrm{~mm}$. The largest cumulative values are obtained when $S=0.5 \mathrm{~mm}$. With all of the models the beginning of external water use is associated with a steep rise in the slope of the cumulative curves. When $S=0.5 \mathrm{~mm}$, all of the cumulative curves cross the measured $E$ curve. When $S=$ $1.0 \mathrm{~mm}$ and (7) is used, the cumulative $E$ is less than the

TABLE 6. Statistics of Model Performance for $Q_{E}$ When the Storage Capacity $(S)$ is Changed for All Surface Types

\begin{tabular}{|c|c|c|c|c|c|}
\hline & \multicolumn{5}{|c|}{$S$ Capacity For All Surfaces, $\mathrm{mm}$} \\
\hline & Small & Base & Large & All & All \\
\hline$S$ pavement & 0.30 & 0.48 & 2.50 & 0.5 & 1.0 \\
\hline$S$ building & 0.25 & 0.25 & 2.50 & 0.5 & 1.0 \\
\hline$S$ coniferous & 0.75 & 1.20 & 2.50 & 0.5 & 1.0 \\
\hline$S$ deciduous* & 0.20 & 0.30 & 0.40 & 0.495 & 0.995 \\
\hline$S$ grass & 0.50 & 1.30 & 7.60 & 0.5 & 1.0 \\
\hline \multicolumn{6}{|c|}{ Hourly Statistics } \\
\hline Mean, $\mathrm{W} \mathrm{m}^{-2}$ & 43.26 & 40.38 & 36.85 & 47.39 & 45.72 \\
\hline $\mathrm{sd}, \mathrm{W} \mathrm{m}^{-2}$ & 59.92 & 58.20 & 56.92 & 63.03 & 62.33 \\
\hline$m$ & 0.84 & 0.83 & 0.82 & 0.87 & 0.87 \\
\hline$r^{2}-2$ & 0.78 & 0.81 & 0.83 & 0.75 & 0.77 \\
\hline RMSE, $\mathrm{W} \mathrm{m}^{-2}$ & 30.16 & 27.65 & 26.48 & 33.40 & 31.71 \\
\hline $\mathrm{RMSE}_{s}, \mathrm{~W} \mathrm{~m}^{-2}$ & 10.66 & 10.72 & 11.75 & 11.15 & 10.13 \\
\hline $\mathrm{RMSE}_{u}, \mathrm{~W} \mathrm{~m}^{-2}$ & 28.21 & 25.49 & 23.73 & 31.49 & 30.05 \\
\hline$d$ & 0.94 & 0.95 & 0.95 & 0.93 & 0.93 \\
\hline N\&S $†$ & 0.77 & 0.81 & 0.82 & 0.72 & 0.75 \\
\hline \multicolumn{6}{|c|}{ Daily Statistics } \\
\hline Mean, $\mathrm{W} \mathrm{m}^{-2}$ & 44.87 & 41.87 & 38.09 & 49.20 & 47.39 \\
\hline $\mathrm{sd}, \mathrm{W} \mathrm{m}^{-2}$ & 25.99 & 23.87 & 23.21 & 29.27 & 28.77 \\
\hline$m$ & 0.97 & 0.93 & 0.92 & 1.04 & 1.05 \\
\hline$r^{2}$ & 0.66 & 0.71 & 0.76 & 0.60 & 0.63 \\
\hline RMSE, $\mathrm{W} \mathrm{m}^{-2}$ & 15.66 & 13.00 & 11.76 & 20.46 & 18.90 \\
\hline $\mathrm{RMSE}_{s}, \mathrm{~W} \mathrm{~m}^{-2}$ & 4.42 & 2.17 & 2.87 & 8.76 & 6.97 \\
\hline $\mathrm{RMSE}_{u}, \mathrm{~W} \mathrm{~m}^{-2}$ & 15.03 & 12.82 & 11.40 & 18.49 & 17.57 \\
\hline$d$ & 0.88 & 0.91 & 0.93 & 0.83 & 0.85 \\
\hline N\&S & 0.48 & 0.64 & 0.71 & 0.12 & 0.25 \\
\hline
\end{tabular}

Deciduous values for summer, using the same headings as above, are $0.60,0.80,0.90,0.5$, and 1.0 , respectively.

*Deciduous value for winter

$†$ Nash and Sutcliffe [1970]. 
TABLE 7. Statistics of Model Performance for $Q_{E}$ When the Drainage Functions are Changed and $S=0.5 \mathrm{~mm}$

\begin{tabular}{|c|c|c|c|c|c|c|c|c|}
\hline & \multicolumn{8}{|c|}{ Drainage Functions } \\
\hline & $\mathrm{v}^{*}$ & $v \dagger$ & (7) $\ddagger$ & $(5) \S$ & (5)\| & $(7) \ddagger$ & $(7) \ddagger$ & $\begin{array}{c}\text { Rutter et al. } \\
{[1971] \rrbracket}\end{array}$ \\
\hline Coefficient $D_{0}$ & $\mathrm{v}$ & $\mathbf{v}$ & 10 & 0.013 & 0.018 & 32 & 12 & 0.0014 \\
\hline Coefficient $b$ & $\mathbf{v}$ & $\mathbf{v}$ & 3 & 1.71 & 1.76 & 1.5 & 1.5 & 5.25 \\
\hline \multicolumn{9}{|c|}{ Hourly Statistics } \\
\hline Mean, $W \mathrm{~m}^{-2}$ & 40.38 & 47.39 & 41.88 & 49.92 & 48.82 & 46.77 & 46.90 & 45.11 \\
\hline $\mathrm{sd}, \mathrm{W} \mathrm{m}^{-2}$ & 58.20 & 63.03 & 59.77 & 65.65 & 64.09 & 61.26 & 61.32 & 60.67 \\
\hline$m$ & 0.83 & 0.87 & 0.83 & 0.88 & 0.87 & 0.84 & 0.84 & 0.84 \\
\hline$r^{2}$ & 0.81 & 0.75 & 0.77 & 0.72 & 0.73 & 0.75 & 0.75 & 0.76 \\
\hline RMSE, $\mathrm{W} \mathrm{m}^{-2}$ & 27.65 & 33.40 & 30.26 & 36.78 & 35.32 & 32.83 & 32.88 & 32.13 \\
\hline $\mathrm{RMSE}_{s}, \mathrm{~W} \mathrm{~m}^{-2}$ & 10.72 & 11.15 & 10.58 & 12.23 & 11.99 & 11.98 & 12.01 & 11.47 \\
\hline $\mathrm{RMSE}_{u}, \mathrm{~W} \mathrm{~m}^{-2}$ & 25.49 & 31.49 & 28.35 & 34.69 & 33.22 & 30.57 & 30.61 & 30.02 \\
\hline$d$ & 0.95 & 0.93 & 0.94 & 0.91 & 0.92 & 0.93 & 0.93 & 0.93 \\
\hline N\&S & 0.81 & 0.72 & 0.77 & 0.66 & 0.69 & 0.73 & 0.73 & 0.74 \\
\hline \multicolumn{9}{|c|}{ Daily Statistics } \\
\hline Mean, $W \mathrm{~m}^{-2}$ & 41.87 & 49.20 & 43.41 & 51.94 & 50.71 & 48.31 & 48.44 & 46.75 \\
\hline $\mathrm{sd}, \mathrm{W} \mathrm{m}^{-2}$ & 23.87 & 29.27 & 26.77 & 28.96 & 28.49 & 28.56 & 28.54 & 27.95 \\
\hline$m$ & 0.93 & 1.04 & 1.01 & 0.97 & 0.99 & 1.03 & 1.04 & 1.02 \\
\hline$r^{2}$ & 0.71 & 0.60 & 0.68 & 0.54 & 0.57 & 0.62 & 0.62 & 0.64 \\
\hline RMSE, $W \mathrm{~m}^{-2}$ & 13.00 & 20.46 & 15.37 & 22.72 & 21.35 & 19.24 & 19.30 & 17.99 \\
\hline $\mathrm{RMSE}_{s}, \mathrm{~W} \mathrm{~m}^{-2}$ & 2.17 & 8.76 & 2.93 & 11.46 & 10.23 & 7.85 & 7.98 & 6.28 \\
\hline $\operatorname{RMSE}_{u}, \mathrm{~W} \mathrm{~m}^{-2}$ & 12.82 & 18.49 & 15.09 & 19.61 & 18.74 & 17.56 & 17.57 & 16.86 \\
\hline$d$ & 0.91 & 0.83 & 0.89 & 0.79 & 0.81 & 0.84 & 0.84 & 0.86 \\
\hline$N \& S$ & 0.64 & 0.12 & 0.50 & -0.09 & 0.04 & 0.22 & 0.22 & 0.32 \\
\hline
\end{tabular}

Here, v stands for variable.

* Base equations with base $S$ capacities.

†Base equations but $S=0.5 \mathrm{~mm}$ for all surfaces

$\ddagger$ Coefficients [Falk and Niemczynowicz, 1978].

$\$$ Coefficients [Calder and Wright, 1985].

||Coefficients [Calder, 1977].

ॠCoefficients [Shuttleworth, 1988].

measured $E$, but by the end of the study period they converge, indicating overprediction in the latter period. The same equation underpredicts the cumulative $E$ when $S=2.0$ $\mathrm{mm}$ but maintains a more similar slope to that of the measured $E$.

This indicates that care must be taken in assigning drainage functions and coefficients. It appears that those selected in this study for the Sunset site simulate the drainage and surface water state well.

\section{Discussion and CONCLUSIONS}

The objective of this study was not to model the evapotranspiration for a particular time and place but to develop a method to continuously model $E$ over a range of meteorological conditions in urbanized terrain. There has been no attempt to calibrate the model to the measured data. Therefore the good performance of the model, using physically realistic input values obtained from the literature, allows us to recommend this type of approach to modeling urban evapotranspiration and surface water state in other cities.

Although the model does well on average it generally underpredicts in the early part of the year and performs better in the spring/early summer in Vancouver. The modeled $Q_{E}$ is always greater than zero because dewfall is not predicted even though it was observed on grass on some nights. This failure is one of the reasons why the model underpredicts in the morning and should be corrected. The measured $Q_{E}$ suggests that dewfall can be an important part of the urban energy and water balances in these months and should not be ignored [Grimmond and Oke, 1986].

If the model is to be applied to other cities, the changes required primarily relate to the assignment of parameter values. From the sensitivity analyses it can be concluded that if the model is to operate well, close attention needs to be paid to the drainage and storage capacities of the dominant surface types. Wetness sensors, located on a number of representative surfaces, appear to be a simple way of assessing the performance of the model, since measurements of $Q_{E}$ are not frequently available.

If the model is applied in other hydroclimatological regimes, for example, in a tropical city, it would be advisable to conduct evaporation measurements so that the surface resistance submodel is appropriate. The robustness of the surface resistance submodel has not been assessed elsewhere. In the tropics and other locations where intense rainfall events occur, further investigation of the Massman [1983] drainage functions, which allow for the inclusion of the intensity of rainfall, may be worthwhile. Snow has been ignored, but its incorporation via an additional submodel should be reasonably easy with the appropriate melt equations. The presence of frozen ground would require further adaptations since the model would have to keep a record of water phases as well as depth within a store.

We conclude that this physically based model is a promising approach to model evapotranspiration and surface water state in urban areas. It has the advantage of being 
dynamically responsive to both meteorological and seasonal conditions. The success of the one layer form of the model suggests that developments to include a multilayer version are worthwhile. The performance of the whole-canopy approach to modeling the surface resistance is encouraging. The statistics indicate that it matches the results for forests, but the robustness of the parameters need to be tested in other urban areas.

Acknowledgments. Special thanks are due to C. J. Souch, H. A. Cleugh, and H. P. Schmid, who helped in the field and for useful discussion. The field site was made available by B.C. Hydro. This work was supported by the Canada Department of Environment (Atmospheric Environment Service) and the Natural Sciences and Engineering Research Council of Canada through grants to T.O. S.G. was the recipient of a University of British Columbia Graduate Fellowship.

\section{REFERENCES}

Alley, W. M., D. R. Dawdy, and J. C. Schaake, Jr., Parametricdeterministic urban watershed model, J. Hydraul. Div. Am. Soc. Civ. Eng., 106(HY5), 679-690, 1980.

Brater, E. F., Steps toward a better understanding of urban runoff processes, Water Resour. Res., 4, 335-347, 1968.

Brutsaert, W., Evaporation Into the Atmosphere, 299 pp., D. Reidel, Hingham, Mass., 1982.

Calder, I. R., A model of transpiration and interception loss from a Spruce forest in Plynlimon, Central Wales, J. Hydrol., 33, 247265,1977

Calder, I. R., and I. R. Wright, Gamma ray attenuation studies of interception from Sitka Spruce: Some evidence for a traditional transport mechanism, Water Resour. Res., 22, 409-417, 1985.

Chandler, T. J., Urban climatology and its relevance to urban design, WMO Tech. Note 149, 61 pp., World Meteorol. Organ., Geneva, 1976.

Cleugh, H. A., and T. R. Oke, Suburban-rural energy balance comparisons in summer for Vancouver, B.C., Boundary Layer Meteorol., 36, 351-369, 1986.

Davies, $H$., and T. Hollis, Measurements of rainfall-runoff volume relationships and water balance for roofs and roads, paper presented at the Second International Conference on Urban Storm Drainage, Urbana, Illinois, 1981.

Denis, J. E., Jr., D. M. Gray, and R. E. Wejch, Algorithm 573 NL2SOL, an adaptive non-linear least squares algorithm, Assoc. Comput. Mach. Trans. Math. Software, 7, 369-383, 1981.

Dolman, A. J., J. B. Stewart, and J. D. Cooper, Predicting forest transpiration from climatological data, Agric. For. Meteorol., 42, 339-353, 1988

Dyer, A. J., A review of flux-profile relationships, Boundary Layer Meteorol., 7, 363-372, 1974.

Falk, J., and J. Niemczynowicz, Characteristics of the above ground runoff in sewered catchments, in Urban Storm Drainage, edited by P. R. Helliwell, pp. 159-171, Pentech, London, 1978.

Gash, J. H. C., An analytical model of rainfall interception by forests, Q. J. R. Meteorol. Soc., 105, 43-55, 1979.

Gash, J. H., and A. J. Morton, An application of the Rutter model to the estimation of the interception loss from Thetford forest, $J$. Hydrol., 38, 49-58, 1978.

Gash, J. H., W. J. Shuttleworth, C. R. Lloyd, J. C. Andre, J. P. Goutorbe, and J. Gelpe, Micrometeorological measurements in Les Landes forest during HAPEX-MOBILHY, Agric. For, Meteorol., 46, 131-147, 1989.

Gay, D. M., Remark on algorithm 573, Assoc. Comput. Mach. Trans. Math. Software, 9, 139, 1983.

Grimmond, C. S. B., The suburban water balance: Daily, monthly and annual results from Vancouver, B.C., M.Sc. thesis, 172 pp., Univ. of British Columbia, Vancouver, 1983.

Grimmond, C. S. B., An evapotranspiration model for urban areas, Ph.D. thesis, 206 pp., Univ. of British Columbia, Vancouver, 1988.

Grimmond, C. S. B., and T. R. Oke, Urban Water Balance 2:
Results from a suburb of Vancouver, B.C., Water Resour. Res $22,1397-1403,1986$

Grimmond, C. S. B., H. A. Cleugh, and T. R. Oke, An objective hysteresis model for urban storage heat flux and its comparison with other schemes, Atmos. Environ., in press, 1991.

Grynning, S. E., A. A. M. Holtslag, J. S. Irwin, and B. Siverstsen, Applied dispersion modelling based on scaling meteorological scaling parameters, Atmos. Environ., 21, 79-89, 1987.

Hall, M. J., Urban Hydrology, 299 pp., Elsevier, New York, 1984

Halldin, S., H. Grip, and K. Perttu, Model for energy exchange of a pine forest canopy, in Comparison of Forest Water and Energy Exchange Models, edited by S. Halldin, pp. 59-75, International Society of Ecological Modelling, Copenhagen, 1979.

Jarvis, P. G., The interpretation of the variations in leaf water potential and stomatal conductance found in canopies in the field, Philos. Trans. R. Soc. London, Scr. B., 273, 593-610, 1976.

Jarvis, P. G., G. B. James, and J. J. Landsberg, Coniferous forest, in Vegetation and Atmosphere, vol. 2, Case Studies, edited by J. L. Monteith, pp. 171-240, Academic, San Diego, Calif., 1976.

Kalanda, B. D., T. R. Oke, and D. L. Spittlehouse, Suburban energy balance estimates for Vancouver, B.C., using Bowen Ratio energy-balance approach, J. Appl. Moteorol., 19, 791-802, 1980.

Kramer, P. J., and T. T. Kozlowski, Physiology of Woody Planıs, p. 64, Academic, San Diego, Calif., 1979.

Lacy, R. E., Climate and building, building research establishment report, $185 \mathrm{pp}$. ., Dep. of the Environ., London, 1977.

Landsberg, H. E., The Urban Climate, 275 pp., Academic, San Diego, Calif., 1981.

Lazaro, T. R., Urhan Hydrolegy: A Multidiscipline Approach, 249 pp., Ann Arbor Science, Michigan, 1979.

Lindroth, A., Canopy conductance of coniferous forests related to climate, Water Resour. Res., 21, 297-304, 1985.

Massman, W. J., The derivation and validation of a new model for the interception of rainfall by forests, Agric. Meteorol., 28. 261-286, 1983.

McCaughey, J. H., D. W. Mullins, and M. Publicover, Comparative performance of two reversing Bowen Ratio measurement systems, J. Atmos. Oceanic Technol., 4, 724-730, 1987.

McIntosh, D. H., and A. S. Thom, Essentials of Meterology, 239 pp., Wykeham, London, 1972.

Mechler, W. A., and D. G. Riecken, Review of methods for computing storm runoff from urban areas: History and state of the art. 57 pp., Greater Vancouver Sewerage and Drainage District. British Columbia, 1977.

Monteith, J. L., Evaporation and environment, Symp. Soc. Exp.

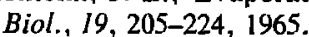

Moore, C., Double-precision routines NL2SOL and NL2SNO, Tech. Note 214, 17 pp., Univ. of British Columbia Comput. Centre, Vancouver, 1986.

Mulder, J. P. M., Simulating interception loss using standard meteorological data, in The Forest-Atmosphere Interaction, edited by B. A. Hutchinson and B. B. Hicks, pp. 177-196, D. Reidel, Hingham, Mass., 1985.

Nash, J. E., and J. V. Sutcliffe, River flow forecasting through conceptual models, part 1 , A discussion of principles, $J$. Hydrol., $10,282-290,1970$.

Nouh, M., Effect of model calibration on the least-cost design of storm-water drainage systems, in Urban Drainage Modeling, International Symposium on Comparison of Urban Drainage Models With Real Catchment Data, '86, Dubrovnik, Yugoslavia, edited by C. Maksimovic and M. Radojkovic, pp. 61-73, Pergamon, New York, 1986.

Oke, T. R., Methods in urban climatology, in Applied Climatology. Zurcher Geog. Schriften, vol. 14, edited by W. Kirchhofer, A. Ohmura, and W. Wanner, pp. 19-29, Eidgenössische Technishe Hochschule, Zurich, 1984.

Oke, T. R., The urban energy balance, Prog. Phys. Geog., 12. 471-508, 1988.

Oke, T. R., and H. A. Cleugh, Urban heat storage derived as energy budget residuals, Boundary Layer Meteorol., 39, 233-245, 1987.

Penman, H. L., Natural evaporation from open water, bare soil and grass, Proc. R. Soc. London, Ser. A., 193, 120-145, 1948.

Pratt, C. J. J. J. Harrison, and J. R W Adams, Storm runof simulation in runoff quality investigations, paper presented at the 
Third International Conference on Urban Storm Drainage, Goteborg, Sweden, June 4-8, 1984.

anderson, D., Atmospheric science and power production, 850 pp., Office of Sci. and Tech. Inf., U.S. Dep. of Energy, Washington, D. C., 1984

Ripley, E. A., and R. E. Redmann, Grassland, in Vegetation and the Atmosphere, vol. 2, Case Studies, edited by J. L. Monteith, pp. 351-398, Academic, San Diego, Calif., 1975.

Ross, S. L., and T. R. Oke, Tests of three urban energy balance models, Boundary Layer Meteorol., 44, 73-96, 1988.

Roth, M., T. R. Oke, and D. G. Steyn, Velocity and temperature spectra and cospectra in an unstable suburban atmosphere, Boundary Layer Meteorol., 47, 309-320, 1989.

Rutter, A. J., K. A. Kershaw, P. C. Robins, and A. J. Morton, A predictive model of rainfall interception in forests, I, Derivation of the model from observations in a plantation of Corsician pine Agric. Meteorol., 9, 367-384, 1971.

Rutter, A. J., A. J. Morton, and P. C. Robins, A predictive model of rainfall interception in forests, II, Generalisation of the model and comparison with observations in some coniferous and hardwood stands, J. Appl. Ecol., 12, 367-380, 1975.

Schmid, H. P., and T. R. Oke, A model to estimate the source area contributing to surface layer turbulence at a point over a patchy surface, Q. J. R. Meteorol. Soc., 116(494), 965-988, 1990.

Schmid, H. P., H. A. Clengh, C. S. B. Grimmond, and T. R. Oke, Spatial variability of energy fluxes in suburban terrain, Boundary Layer Meteorol., 54, 249-276, 1991.

Sellers, P. J., and J. G. Lockwood, A computer simulation of the effects of differing crop types on the water balance of small catchments over long time periods, Q. J. R. Meteorol. Soc., 107, $395-414,1981$.

Sellers, P. J., Y. Mintz, and A. Dalchen, The design of the simple biosphere model $(\mathrm{SiB})$ for use in general circulation models, $J$. Atmos. Sci., 43, 505-531, 1986.

Shuttleworth, W. J., Experimental evidence for failure of the Penman-Monteith equation in partially wet conditions, Boundary Layer Meteorol., 10, 91-94, 1976.

Shuttleworth, W. J., A simplified one-dimensional theoretical description of the vegetation-atmosphere interaction, Boundary Layer Meteorol., 14, 3-27, 1978.

Shuttleworth, W. J., Evaporation, Rep. 56, 61 pp., Inst. of Hydrol., Wallingford, UK, 1979.

Shuttleworth, W. J,, Evaporation models in the global water budget, in Variations in the Global Water Budget, edited by A. Street-Perrott, M. Beran, and R. Radeliffe, pp. 147-171, D. Reidel, Hingham, Mass., 1983.

Shuttleworth, W. J., Evaporation from Amazonian rainforest, Proc. R. Soc. London, Ser. B, 323, 321-346, 1988.

Shuttleworth, W. J., Micrometeorology of temperate and tropical forests, Philos. Trans. R. Soc. London, Ser. B, 324, 199-224, 1989.

Sman, H. T., C. C. D. F. van Ree, and M. Loxham, Water balance techniques applied to industrial complexes, paper presented at the Intemational Symposium on Hydrological Processes and Water
Management in Urban Areas, UNESCO, Duisburg, Federal Republic of Germany, April 24-29, 1988.

Stewart, J. B., Measurement and prediction of evaporation from forested and agricultural catchments, Agric. For. Manage., 8 , $1-28,1984$.

Stewart, J. B., Modelling surface conductance of pine forest, Agric. For. Meteorol., 43, 19-35, 1988.

Stewart, J. B., and H. A. R. de Bruin, Preliminary studies of the dependence of surface conductance of Thetford forest on environmental conditions, in The Forest-Atmosphere Interaction, edited by B. A. Hutchinson and B. B. Hicks, pp. 91-104, D. Reidel, Hingham, Mass., 1984.

Street, H. E., and H. Opik. The Physiology of Flowering Plants: Their Growth and Development, 3rd ed., 297 pp., Edward Arnold, Baltimore, Md., 1984.

Thom, A. S., Momentum, mass and heat exchange of vegetation, Q.J. R. Meteorol. Soc., 99, 154-170, 1972

Thom, A. S., and H. R. Oliver, On Penman's equation for estimating regional evaporation, Q.J. R. Meteorol. Soc., 103, 345-357, 1977.

van den Ven, F. M. H., Urban hydrological cycle, paper presented at the International Symposium on Hydrological Processes and Water Management in Urban Areas, UNESCO, Duisburg, Federal Republic of Germany, April 24-29, 1988.

van Ulden, A. P., and A. A. M. Holtslag, Estimation of atmospheric boundary layer parameters for diffusion applications, $J$. Clim. Appl. Meteorol., 24, 1196-1207, 1985.

Weiss, A., and D. L. Lukens, An electronic circuit for the detection of leaf wetness and a comparison of 2 sensors under field conditions, Plant Dis., 65, 41-43, 1981 .

Wenzell, H. G., and M. L. Voorhees, Adaptation of ILLUDAS for continuous simulation, J. Hydraul. Div. Am. Soc. Civ. Eng., 106(HY 11), 1795-1812, 1980.

Willmott, C. J., On the evaluation of model performance in physical geography, in Spatial Statistics and Models, edited by G. L. Gaile and C. J. Willmott, pp. 443-460, D. Reidel, Hingham, Mass., 1984.

Wright-McLaughlin Engineers Limited, Urban Storm Drainage Criteria Manual, 2 vols., Denver Regional Council of Governments, Colo., 1969

Zinke, P., Forest interception studies in the U.S., in Forest Hydrology, edited by W. E., Sopper and H. W. Lull, pp. 137-161, Pergamon, New York, 1967.

C. S. B. Grimmond, Climate and Meteorology Program, Department of Geography, Indiana University, Bloomington, IN 47405.

T. R. Oke, Atmospheric Science Programme, Department of Geography, University of British Columbia, Vancouver, B.C., Canada V6T 1W5.

(Received September 10, 1990; revised February 11, 1991; accepted February 15, 1991.) 